A major purpose or the I ecnnlcal Information Center is to provide the broadest dissemination possible of information contained in DOE's Research arid Devalnpment Reports to business, indus $y$, the academic community, and federal, state and local governments.

Although a small portion of this report is not reproducible, it is being made available to expedite the availability of information on the research discussed herein. 
LA-UR $-82-3411$

L/I-UR--82-3411

DE83 003555

TITLE: COMPARISON OF TWO SLIDELINE MFTHODS USING ADINA

AUTHOR(S): Francisco M. Guerra and Richard V. Browning

SUBmitted to Nonlinear Finlto lidment Analys ls and ADINA Conference, Cumbridge, MA, June 15-17, 1983.

\section{Motice}

PORTIONS OF THIS REPORT ARE ILLEOIRLE. II

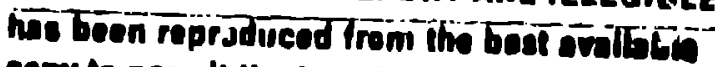

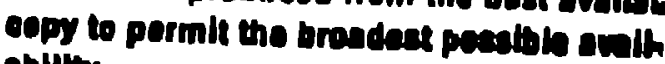
ablitiv.

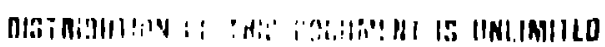

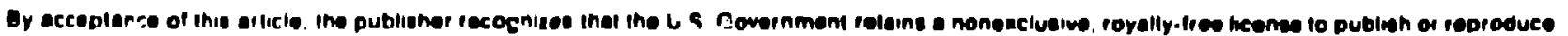

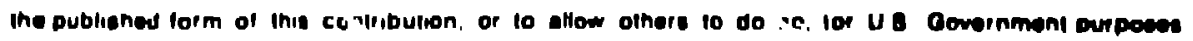

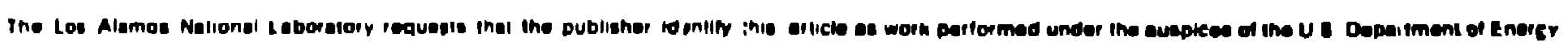

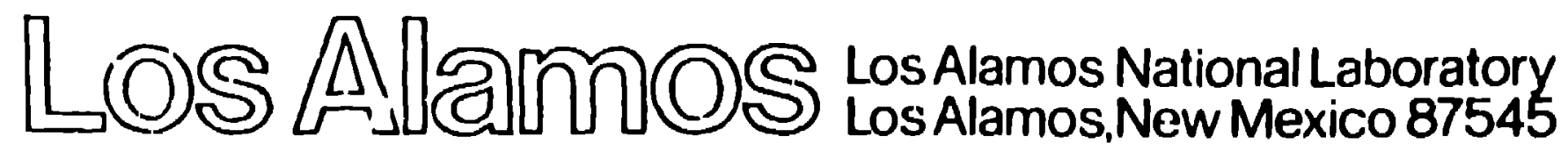




\title{
COMPARISON OF TWO SLIDELINE METHODS USING ADINA
}

\author{
Francisco M. Guerra \\ and \\ Richard V. Browning \\ Analysis and Testing Group (WX-11) \\ Design Analyois Division \\ Los Alumos National Laboratory \\ Los Alamos, NM 87545
}

\begin{abstract}
Abetract - Two general mechods of treating sliding interfuce problems werc impleinented in ADINh. The first method uges constraint equations and is based on the work of Taylor, Hughes, et al. The second method is a penalty function method where finita: stifinesses are used to rimulnte the contuct forees. This is similar to the methosl uacel by llallquist in NIRlizn. 'Thess' may bo lased ne notension Hlidiny, inrerfacen, with or withome rriction, or as a non-aliding interface to interpoliten betwerel di flerenl menl, regions. Wo briefly reviow

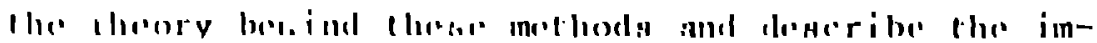
plementalion in ADINA. Sevoral npplidention problons hive buell run, including, inclial forming, problems.

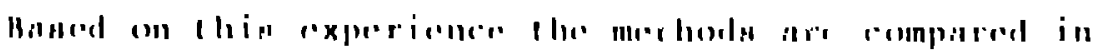

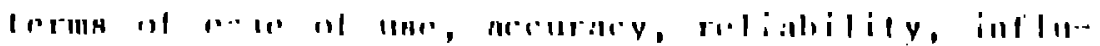

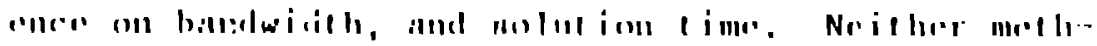

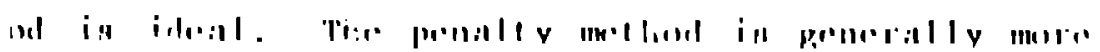

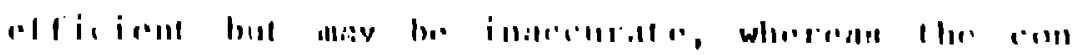

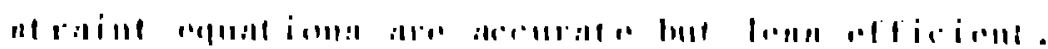




\section{Introduction}

Slidelines have a long history of use in explicit finila difference wave propagation programs, to model material discontinuities, and as a mesh grading technique. Their use in more conventional atructural anslygis has been much more limited, basically because reliable alporithms for slidelines have not been implemented in widely used finite element programs. This lack of olidelines in otructural programs results from the inherent difficulty of providing this feature, not from its unimportance.

The concept of olidelines, that ia, material surfaces that can olide with respect to one nnother, perhars with friction, is important to many classcs of problems. For exnmple, metal forming procesaes, impact problems, mechnnism degign, na well as soil atructure and geologic problems. Some problems that are restrictol to mall relative motions, or in which ono surFace in rigid, can be molved using sinple dinplacement conetrainta or truas

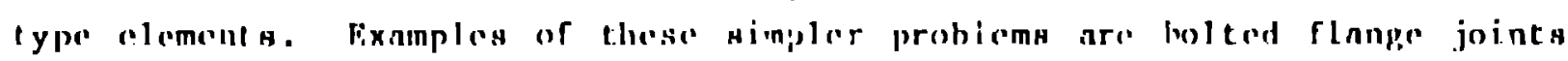

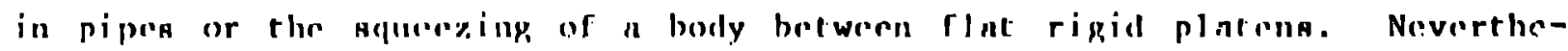

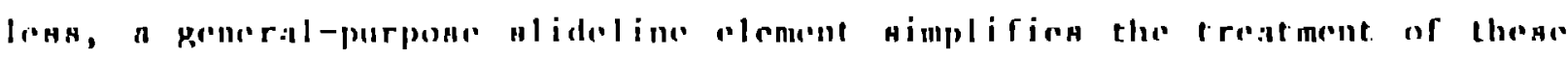
probleme and allowe for many more poneral aolutione de woll.

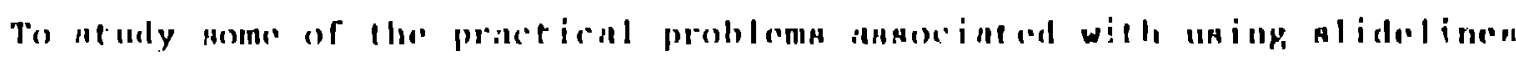

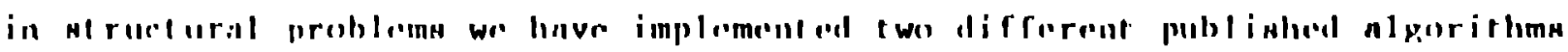

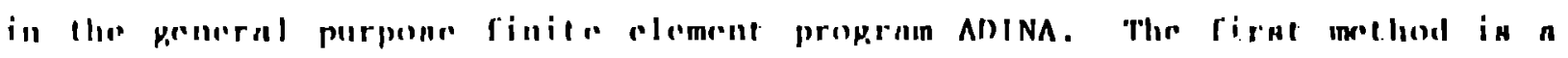

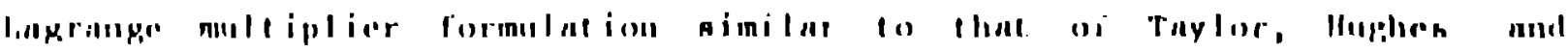

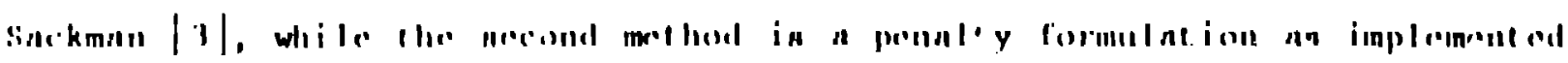

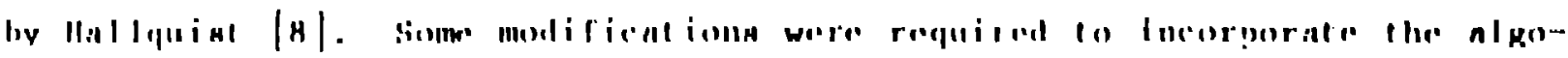

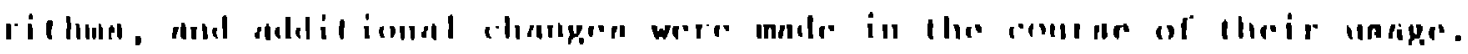


We will first, ' 'w the theory behind the methods, then show several examples of their use. Ima examples are contrived, but most are actual applicalions. Finally, we ill review the results and cumpare the methods from the standpoint of efficienr., reliability, and ease of uge.

\section{Lagrange Multiplier Method}

The basic idea of the Lagrange Multiplier formulation is the addition of a term of the form

$$
\int_{c} \underline{x} \cdot\left(\underline{x}^{1}-\underline{x}^{\prime}\right) \mathrm{dc},
$$

to $n$ otandard variational formulition tor two independent bodies (oee [3] for furthor details). The surface $c$ ig the contact regic, between the deformed bodies, $h^{\prime}$ and $h^{\prime}$, of tho bodieg $h^{l}$ and $s^{\%}$, as shown in Fig. l. The enforcernent of compatibility slong the surface $c$ will then be achicued by taking, independent veriatione of $t$ ( $x^{\prime 2}$ nre the deformed conrilinnteg of material pointe in body a wilh pointe $x$ being nlive noder nud $x^{\prime}$ manter

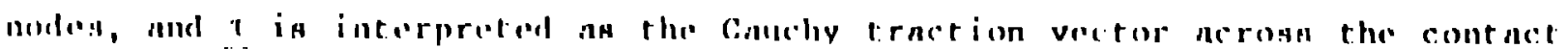
HIII (IIII)

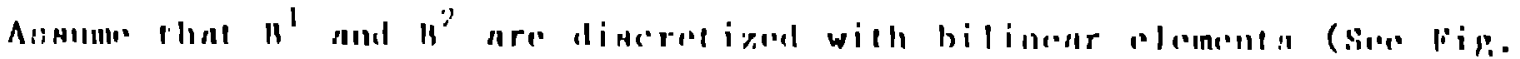

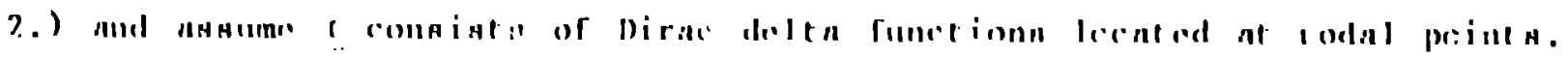

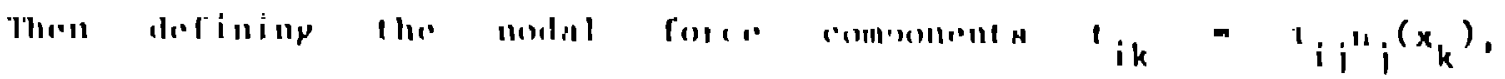
hreorinon

$$
\sum_{i=1}^{N}\left|i_{i}\left(x_{i}^{1}-x_{i}^{\prime}\right)+1_{i}\left(v_{i}^{1} \cdot v_{i}^{\prime}\right)\right|
$$

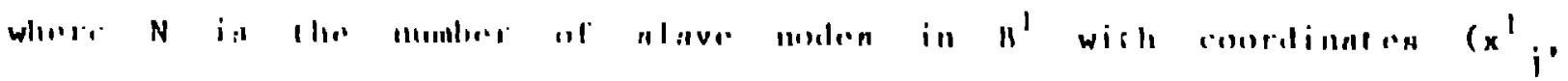

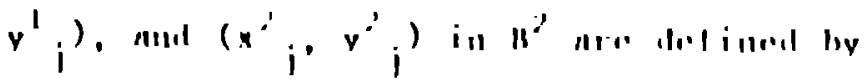




$$
\begin{aligned}
& x_{j}^{2}=N_{1}^{l-1} \text { (a) } x_{l-1}^{2}+N_{2}^{l} \text { (a) } x_{l}^{2} \\
& y_{j}^{2}=N_{1}^{l-1} \text { (a) } y_{l-1}^{2}+N_{2}^{l} \text { (a) } y_{l}^{2}
\end{aligned}
$$

where $\left(x_{\ell-1}^{2}, y_{\ell-1}^{2}\right),\left(x_{\ell}^{2}, y_{\ell}^{2}\right)$ are master node coordinates,

$$
\begin{aligned}
& N_{1}^{l-1}(a) \text { and } N_{2}^{l}(a) \text { are the linear shape functions } \\
& N_{1}^{l-1}(a)=\frac{(1-a)}{2} \quad N_{2}^{l}(a)=\frac{(1+a)}{2}
\end{aligned}
$$

and assuming that $\left(x_{c}, y_{c}\right)$ is the contact or penetration point of $k$ un $\ell-1, \ell$,

$$
y=\frac{2 \cdot\left[\left(x_{c}-x_{\ell-1}\right)^{2}+\left(y_{c}-y_{\ell-1}\right)^{2}\right]^{1 / 2}}{\left[\left(x_{\ell}-x_{\ell-1}\right)+\left(y_{\ell}-y_{\ell-1}\right)^{2}\right]^{1,1}}-1
$$

The tij are interpreted as nodal contact forces and are unknowne to be nulited to the list of oiher notil viriablen, i.e., displacements.

Fur friction, (1) and (2) are cast in normal nnd tangential a-ma.

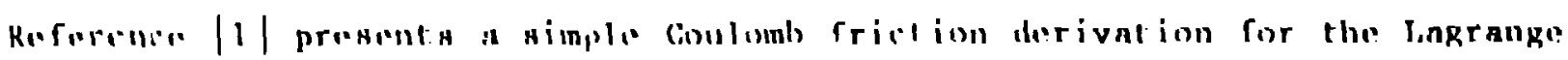

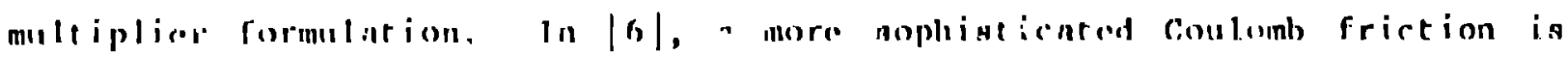
prenentod for unilaternt contale.

Pronal ty Punct ion Mre+lond

The batic iden of thin formulation in the melition to li," variational rgunt ion of a tarm of the rorin 


$$
e^{-1} \int_{c}\left(\underline{u}_{n}-\underline{g}_{0}\right) \underline{u}_{n} d c
$$

where $e^{-1}$ is the penalty multiplier, $u_{n}$ is the normal displacement on the boundary $C$, and $g_{0}$ is the initial gap $[10]$. Another way of viewiag (4) is the insertion of a linear interface spring into the stiffness matrix that couples the penetrating node to two adjacent nodes on the contact surface $[7]$.

Oden [9] takes $E^{-1}$ as the foundation or master uurface modulus, whereas Hallquist [7] has found that a contact area weighted bulk modialus is more robust especially when there is plastic deformation of the master surface.

For friction pronlems, Hallquiat |7] uscs a tangential spring proportional to the normal springs and the relative tanpgential motion of the contilteor node. In $|11|$, on the other hand, the frictionless problem solution is used at a first approximation of the normal contact pressure, which ia

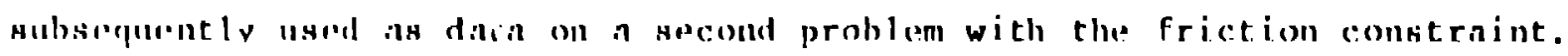

Imnlemenration in AnINA

The implennentiation of the lathringe mol, iplior or the pennley function

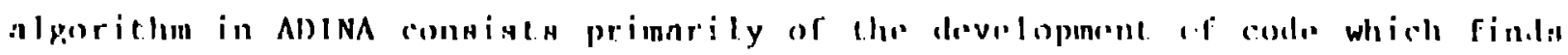

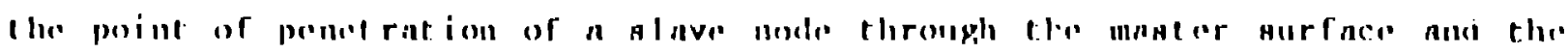

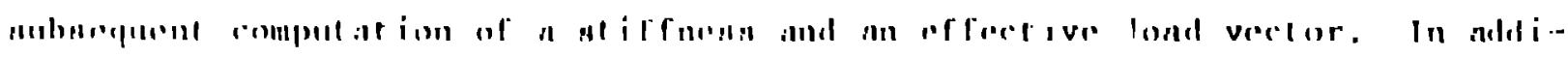

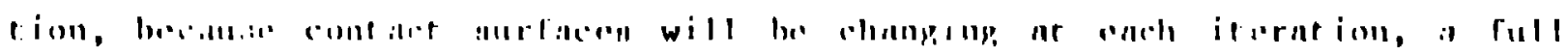

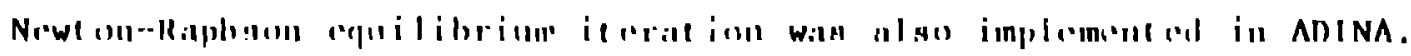

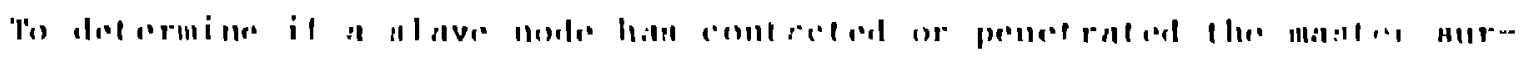

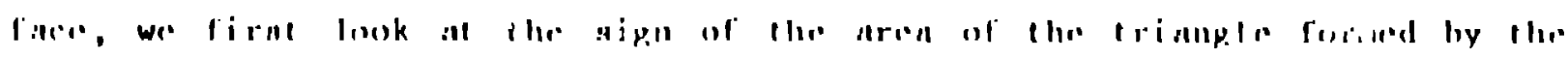


slave node and two master nodes. Let nodes $(\ell-2, \ell-1, \ell, \ell+1)$ define the master surface and nodes $(k-1, k, k+1)$ be slave nodes. See Fig. 3. (For

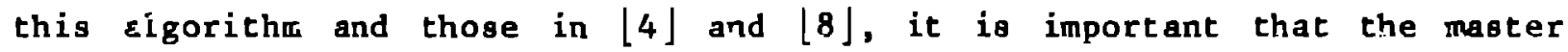
nodes be defined such that the interior of the magter surface be to the right as the nodes come up.) To see if the slave node is interior to the master surface, we compute the area of the triangle ( $k, \ell, \ell-1$ ) (slave, 2nd magter node, lot mater node). If the area is positive (e.g., $(k, l, \ell-1)$ are counterclockwise), then theie is a posaible penetration. If the area is negative, such as for $(k+1, \ell-1, \ell-2)(e . g .,(k+1, \ell-1, \ell-2)$ are clockwise), then the slave node is eiterior to this segment of the master surface.

For slave nodes that puss the area test, two schemes are used to find the contact or penetration point. If the olave node was not in contact for the preceding atep or iteration, then the trajectory of the slave node is checked for an intercept with the master ourtace. If the slave ade was in contact or if it failed the intersection test for all master surface segments, then the slave node locution is projected onto the nearest master surEaco segment. If the prijectid location is outside the range of the master hurface then the alave node in relaned.

Once the contact locntion of the slave noile ia known, thr incremental equntions for the langrange multiplicr are (aee $|1|,|3|$, or $\mid 13\rfloor$ for more detoils.):

$$
K_{-H} \Lambda_{-H}^{(i)}=P_{n}-\frac{F}{H}
$$

where su in the increment al dimpliacenent vectors 


$$
\left.\Delta u^{(i)}={ }_{k}^{t}{ }_{k}^{(i)}, \Delta_{k}^{(i)}, \Delta u_{\ell-1}^{(i)}, \Delta \omega_{\ell-1}^{(i)}, \Delta u_{\ell}^{(i)}, \Delta \omega_{\ell}^{(i)}, \Delta t_{1 k}^{(i)}, \Delta t{ }_{2 k}^{(i)}\right]^{t},
$$

$P_{B}$ is tice external force vector arising from the internal state of stress in the interface elements, $K_{s}$ is an $8 \times 8$ stiffness matrix that is assembled into the slobal stiffness matrix, and $F$ is a force vector that afds ir.to the out-of-balance loads. Here $\underline{R}_{g}$ and $\underline{F}_{g}$ depend on whether the $k^{\text {th }}$ slave note is in contact on segment $\ell-l, l$ and the contact constraint (Fig. 3). Appendix A gives the forms that $\underline{K}$ and $\underline{F}_{g}$ take for various conditions.

For the penalty function impleinentation, the algorithms used in NIKE2D [8] were ugsd with glight modifications for AbINA (eee references [8] and [9] for more details on the deveiopment, implementation, and eatrictions of the algorithm). A contact stiffress and a force vector similar to those in (5) are computed for slave uodes witich a... found in contact. Although NIKE2D inakes thr slideline symutric ly considering the master surface nodes as slave nodes to the slave surface automatically, in the ADINA implementation we left it up to the user to diffine a new slideline with the same result. Becauss there are no contact forces, the force vector lins only 6 elemence and the el friness in a $6 \times 6$ matrix, i.e.,

$$
\left.\Delta u_{H}^{(i)}=\mid \Delta u_{k}^{(i)}, \Delta \omega_{k}^{(i)}, \Delta v_{l-1}^{(i)}, \Delta \omega\right)_{l-1}^{(i)}, \Delta v_{l}^{(i)},\left.\Delta \omega_{l}^{(i)}\right|^{t}
$$

Appendix is gives the form $\underline{K}_{-}$and $\underline{F}_{-}$take for the punilty iunction nitle! ine implrmenterl. 
EXAMPLE PROBT.EMS

\section{Example 1: Ring Sliding on Cylinder.}

Figure 4 shows the mesh for this problem, the location of the slidelines between the slider on the cylinder, and the ring on the slider. A radial pressure was applied as shown on the ring and a prescribed displacen :nt was imposed on the slider. Figures $5 a$ and $5 b$ show von Mises contour ploto at full radial pressure of 30,000 psi for the Lagrange multiplier and penalty function olidelines, respectively. The slight but noticeable differeice in the contoirs is calsed by the different effective otiffnesses of the two methods. Figure 6 is a time history of the radial stress of node 166 for the t: , methods showing the smoother response of the penalty method, as one would expect from itg lower effective otiffness. Figure 7, showing considerable chatter, is a history plot of the radial contact force $r$ the nodes in the vicinity of node 166 for the Lagrange multiplier glidelines . For this problem, the nodes at the top of the slider lift off the cylinder at an earlier time for the lagrange !nultiplier.

\section{Example 2: Con'entric Spheres With Tnternal Presoure.}

Figures $8 a$ and $8 \mathrm{~b}$ show the meshes for two concentric spheres separated by a gmall gap. Internal pressure on thi inner sphere cause plastic deformation of the inner nhell and subsequent loading of the outer shell. This problem shows very interesting effects of small discrepancies in the initial mesh. Figure 9 shows the motion of the slave (node 5) and master nodes (nod's 277) for mesh 1 . They never contact because the olideline is curved in this 
problem, and the mesh grading is not uniform on the two surfaces. Figure 9 shows atress concentration points of contact for mesh 1 . Figure 10a shows the motion for the same nodes in mesh 2. The implementation or the penalty function inserts a spring when the slave node is "close" to the master surface and thus gives an early contact and late release as seen in Fig. $10 \mathrm{~b}$.

\section{Example 3: Superplastir. Sheet Metal Forming Problem.}

In this problem a un.form pressure is epplied over the top surface of a sheet of metal supported above a roughly hemispherical cavity. Fig. 11 shows the arrangement and initial mesh. In the actual problem the metal is heated to a carefully chosen temperature so that the superplastic effect obtained with scme metals will allow the sheet to be deformed into the cavity in a reasonable period of time, without instabilities resulting in grose thickness variations or rupturing of the sheet.

Solving this problem with ADINA required not only the slideline modifications but also large deformation presoure and large deformation creep modifications. To date, we have solved this problem with assumed prjperties for the sheet metal simply co demonatrate the ability of the program to solve this type of problem. Although this might not be realistic for any particular metal it does make an excellent teat of the slideline routines.

In our initial runa on this prohlem we hal considerable trouble with spurius penetration of nodes. This resultrd in an apparent necking when the slideline algorithm noticed the penetrat ed node and pushed it hack out to the surface. Ihis penetration was traced to the villue ubed for the repenetrat ion tolerance in the olideline. Originnlly we assuncd this might have been cauped 
by a material instability. Only through a very detailed examinat Lor of t'ee deformation process did we finally identify the actual error.

Given appropriate constants tor the slideline parameters and the material properties for the sheet, the problem is hancled easily, ar ohown in Eig 12 .

\section{Example 4: Rolling Diaphragm.}

This problem is related to creating an environmental seal between .2 plunger and a vessel. This is done by using a thin metal membrane to connect the two parts, thus requiring the membrane to roll lack on itgelf. Figures 13 and 14 show the initial configuration and a series of deformed shapes as the plunger is noved downward by a prescribed displacement. The slidelines are required to confine the membiane between the tube and the hole in the vesgel. In plane geometry this problem would be fairly simple, but in axisymmetric geometry the selection of the roll radii and thickness of the membrane is difficult because of the geometric constraints.

The combination of material instabilities and slide? ne behavior has made this a most difficult problem for us to solve.

\section{SUMMAKI AND CONCLUISIONS}

In comparing the two slideline methods, we found that both methods had advantages and dishdvantages which, depending on the particular problem consillered, could make either one look good or bad. For example, the Lagrange multiplier method satisfies the contact constraint more precisely and there is no need to determine or input a "spring constant." On the other hinc, it 
adds extra degrees of freedom requiring additional storage and computation. In addition, the Lagrange multipiier method is not symmetric, berause a slave. node cannot contact iwo master surfaces at the same time; neither can a slave node imultaneously be a master node. As a resulc, when using the Lagrange multiplier method, intersecting slidelines are not always possible.

The penalty function slileline has the advantage that no extra degrees of freedom are introduced, and thus no extra storage requircment and fewer computations. Slidelines can intersect, and for a given problem a solution is assured with sufficiently soft springs. On the other hand, the analyst may bare to solve the problem several times to get a goor. solution, hecause of required adjugtments to the spring constants to minimize unacceptible penetrations of slave nodes. In addition, the solution nily converge very slowly or not at all if the stiffuess is as high as degirid.

In our implementition of the two methods we round thit two nrois wiere very significant in the results of the methods. They wore lhe check for e:mtact and/or penceliation and the check for release of the node. Wo foumd that

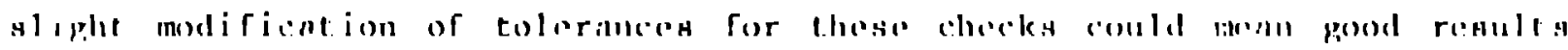

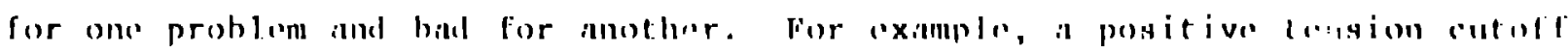

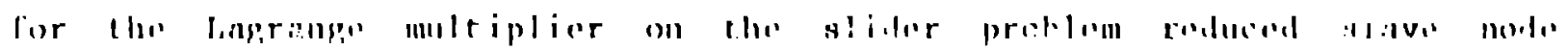

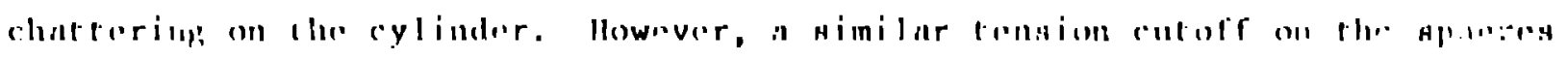

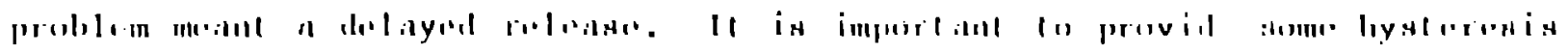

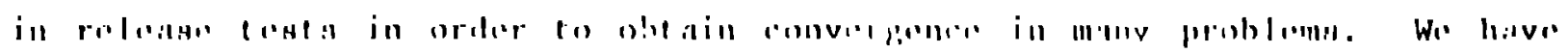

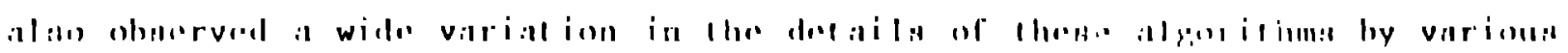

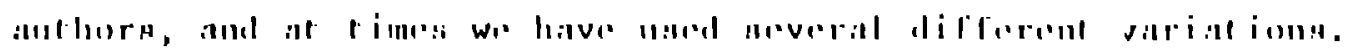

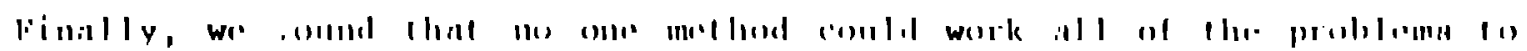

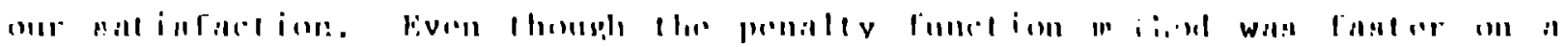

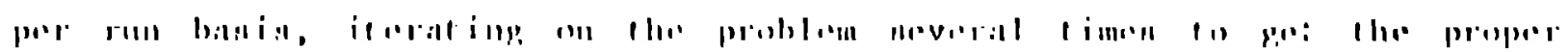


:tiffness negated its efficiency. Interestingly enough, we also found that the two me coods implemented in ADINA could work well together. In mot of the ceses where either method had difficulties, we found that the algorithm implementation was ihe cause of the problem.

\section{REFPRENCES}

1. T. J. R. Hughes, R. L. Taylor, W. Kanoknukulchai, "A Finite rlement Method for Larse Diaplacement Contact and Impact Problema," in Formulationg and Computational Algorithms in Finize Filement Analygia, $K . J$. Bathe, .1. T. Oden, and W. Wunderlich, Fds., Proc. U.S.-Germany SymposiIIm, MIT, Auguat 1976.

2. T. J. R. Ilughes, R. L. Taylor, J. L. Sacliman, A. Curnior, nnd w. Kanoknukulehai: "A Finite Filement Method for a Clane of Contact-Tinpace Probloms," i.n Gomputer Methode in Applicol Mochnnica nnd lingincoring, 1976, Vol. 8, ip $2,49-276$.

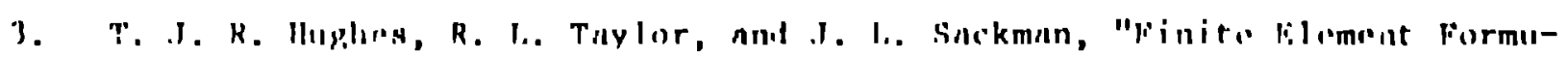

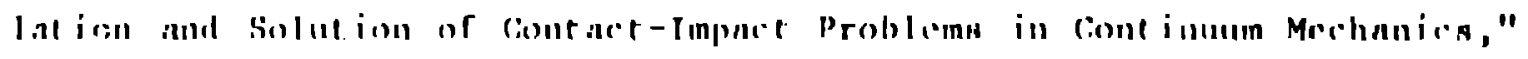

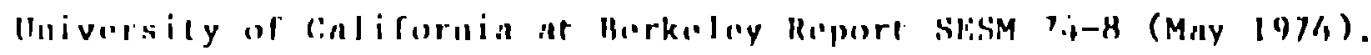

4. I'. I. 4. Huphın, K. I.. Tnylur, I. I., Snckman, mul W. Knnokmukulehui,

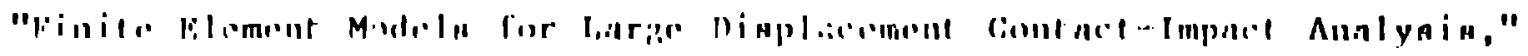

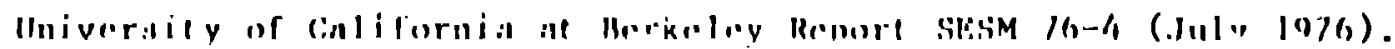

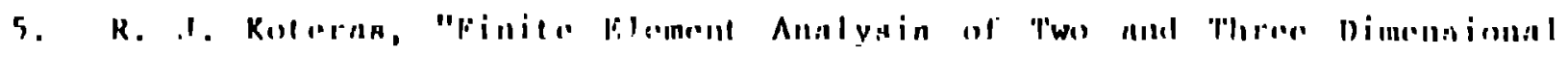

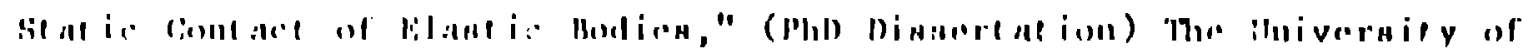

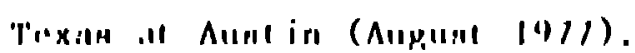


6. I. M. Taylur, "A Finite Flement Analysis for Larpe Deformation Metal Forming Problems Involving Contact and Friction," The University of Texas at Austin TICOM Report 81-15 (Cecember 198L).

7. J. O. Hallquist, "A Numerical Treatment of Sliding Tnterfaces and Impact," in Computational Techniques for Interface Problems, $K$. C. Park and D. K. Gartling, F,de., AMD Vol. 30, ASMF (1978).

8. J. 1). Hallquist, "NIKli2D: An Impli 't, Finite Deformation, FiniteFloment colle for Analyzinp the sentir and Dynamic Reaponae of l'wonimentional Solids," Ladrence: Tivermore National Laburatory Report (Rouph nrilft) (IOH2).

9. J. T. Oden, N. Kikuchi, nnd Y. I., Somp, "Roduced Tutopration and Fixteri-

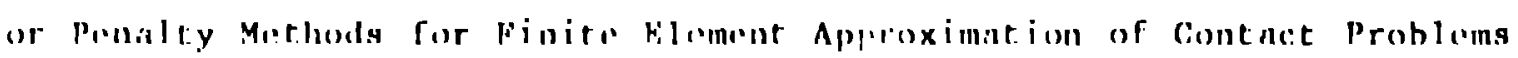

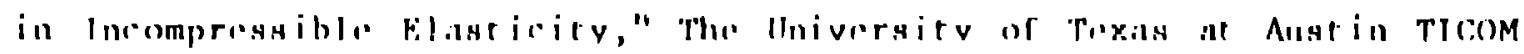
Ripurl $8(1)-2$ (Marih lohl)).

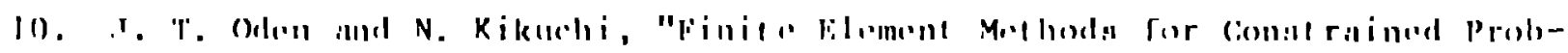

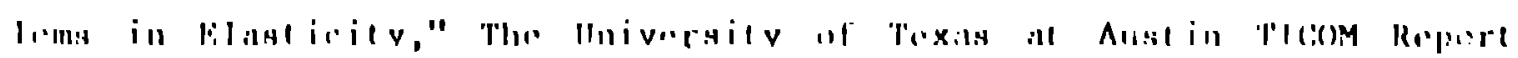
$31 \cdots 10(.1111,1981)$.

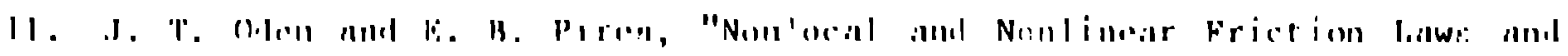

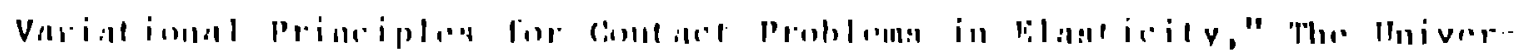

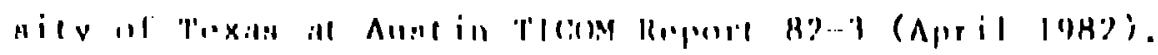

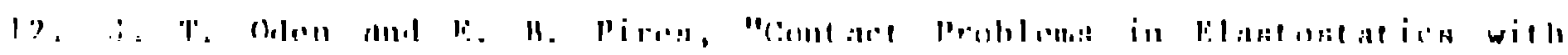

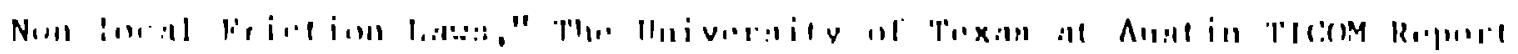

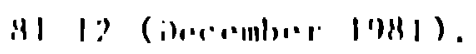

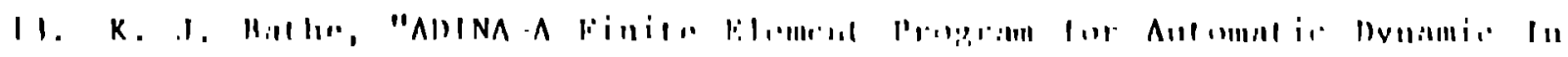

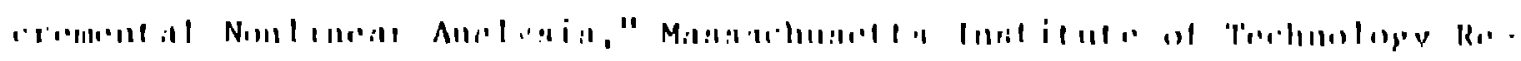

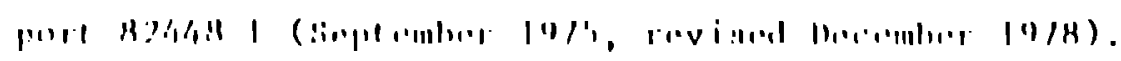


APPENDIX A

lagrange Multiplier Contact St iffiness

and nut-of-Dalance Force Contribution Matrices.

In the subsequent equations we will consider only slave node k and mastar surface segments $\ell-1, \ell$ and $\ell, \ell+1$ and the "(i)" iteration superscript will be omitted for the sake of clarity. That is, all nodal coordinates have be on updated to the current configuration. In addition, we lot $N_{1}=N_{1} l-1$ (i) (i) and $N_{2} l=N_{2}(a(i))$ (ace equation $(h)$ ).

1. Is Cont act Conitition

When there is no contact, then Es and $\underline{K}_{\text {B }}$ taro

$$
\begin{aligned}
& \left.\sum_{-i}^{r}=\mid 0,0,0,0,0,0,0,0\right), \mathrm{iml}
\end{aligned}
$$

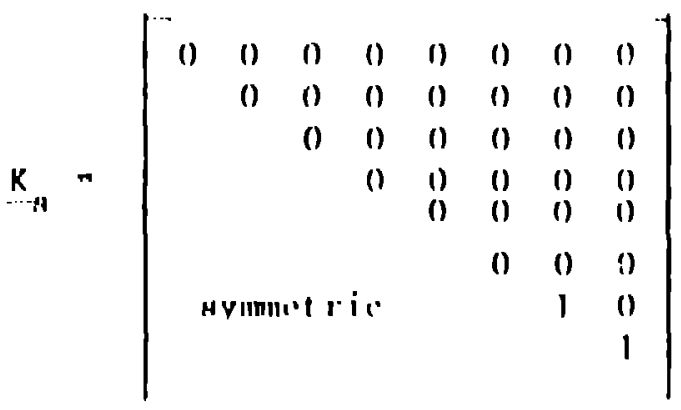

7. St irk coalition

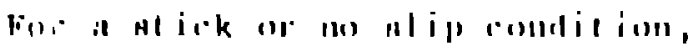

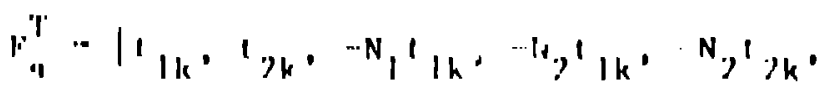

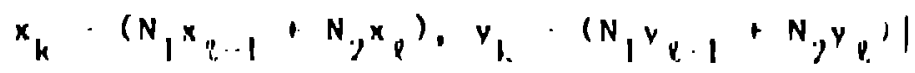




$$
\underline{\mathbf{K}}_{\mathbf{s}}=\left[\begin{array}{cccccccc}
0 & 0 & 0 & 0 & 0 & 0 & 1 & 0 \\
& 0 & 0 & 0 & 0 & 0 & 0 & 1 \\
& & 0 & 0 & 0 & 0 & \mathrm{~N}_{1} & 0 \\
& & & 0 & 0 & 0 & 0 & \mathrm{~N}_{1} \\
\text { s.jmmetric } & & 0 & 0 & \mathrm{~N} \\
& & & & & & 0 & 0 \\
& & & & & & & 0
\end{array}\right]
$$

3. Priction

For the friction or slip constraint lat 0 denote the nngle between segment $\ell-1, \ell$ and the $x$-ilxis, ineisured counterclockwisu from $x$ (fige. 3), then

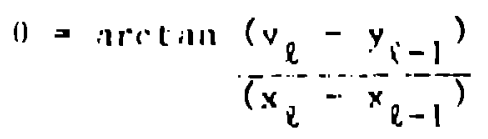

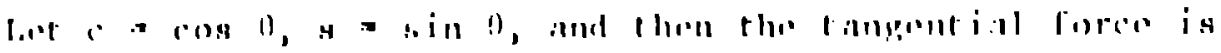

$$
\eta_{k}: 11 \mathrm{l}+1 l_{2 k}
$$

ninl Ine amrmal forere is

$$
r_{k}=a 1 k+1,2 k .
$$

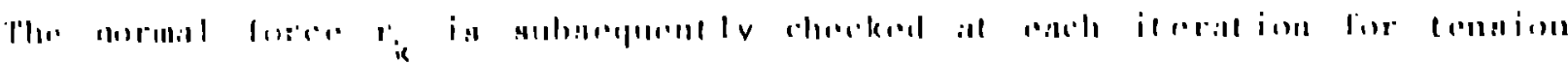

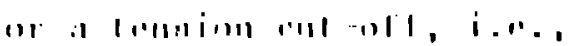

$$
r_{k}: r^{\prime} \quad \text { whr. }
$$

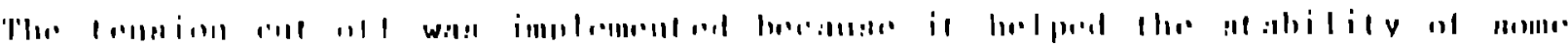

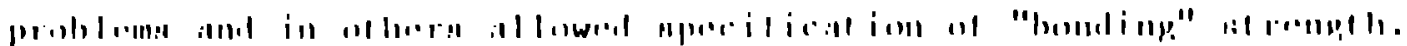

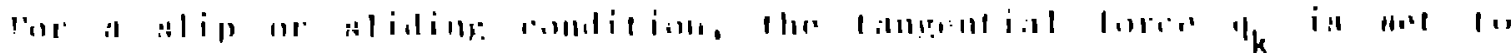

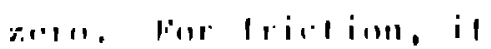




$$
\left|q_{k}\right|>\mu_{g}\left|r_{k}\right| \text {. }
$$

where $\mu_{g}$ is a gtatic coefficient of friction, then $q_{k}$ is recomputed as

$$
\eta_{k}^{*}-\|_{d} \operatorname{aign}\left(q_{k}\right) \cdot\left|r_{k}\right|
$$

where $M_{d}$ is the dynamic coefficiont of friction. If (A.6) is not true, then thr. stick condition (1.2) is imposed.

If the slave node is sliding with friction (e.g., use $q_{k}$ * for tanpential force) or wirhout (aet ${ }_{k}^{*}=0$ ) ther the force vector and atiffness matix are

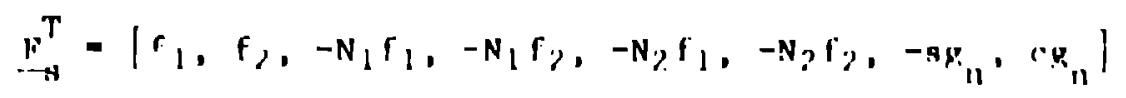

where

$$
\begin{aligned}
& r_{1}=\mathrm{Cu}_{k}+i r_{k}, \quad r_{1}=-H_{1} I_{k}+r r_{k} \text { nnd } \\
& y_{11}=\mid-3 x_{k}+1 \cdot v_{k}-N_{1}:-n x_{l-1}+\left(\cdot v_{l-1}\right)-N_{2}\left(-3 x_{l}+\left(y_{l}\right) \mid\right.
\end{aligned}
$$

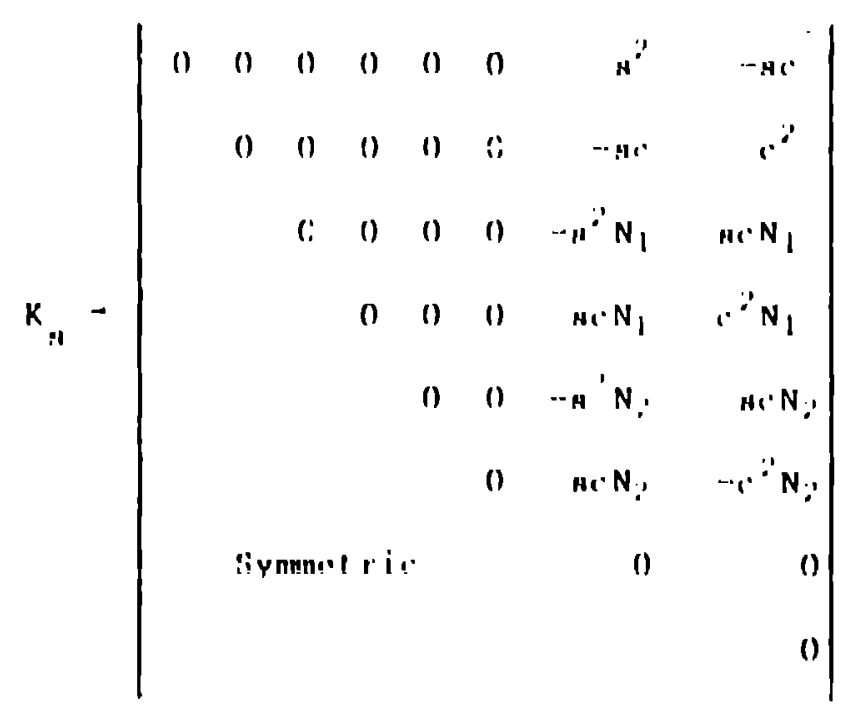

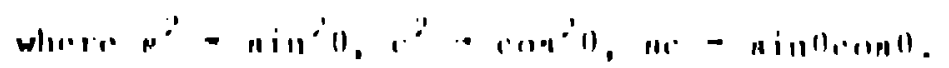




\section{APPFNDIX B}

\section{Penalty Function Contact Stiflness}

\section{and Out-of-nalance Force Contribution Matrices.}

II: ing: the notntion in $|8|$ and letting

$$
A=\frac{\left.\mid\left(x_{c}-x_{\ell-1}\right)^{2}+y_{c}-y_{\ell-1}\right)\left.^{2}\right|^{1 / 2}}{\left.\mid\left(x_{\ell}-x_{\ell-1}\right)^{2}+y_{\ell}-y_{\ell-1}\right)\left.^{2}\right|^{1 / 2}}
$$

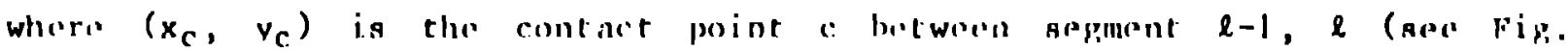
3), tho stiffuess inntrix is

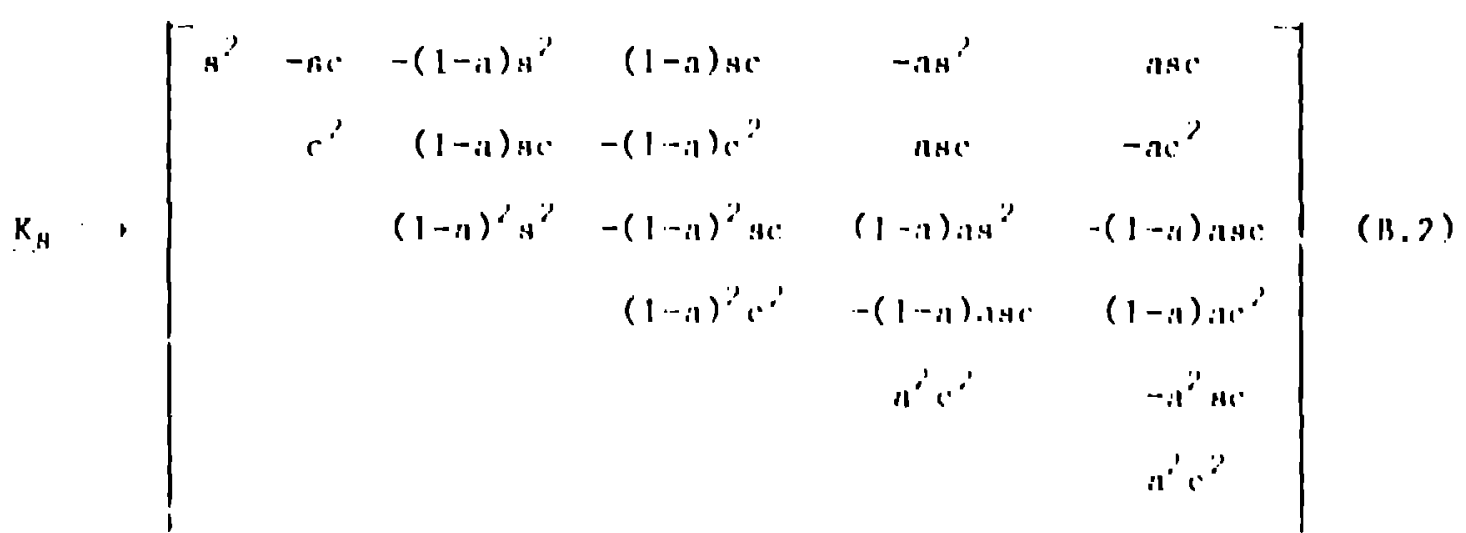

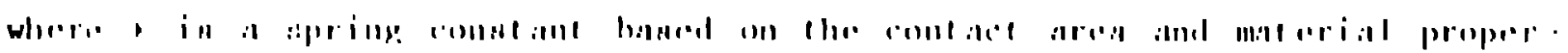

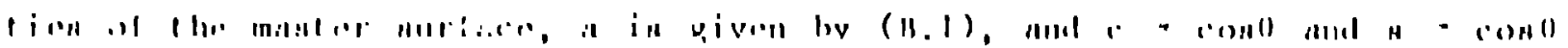

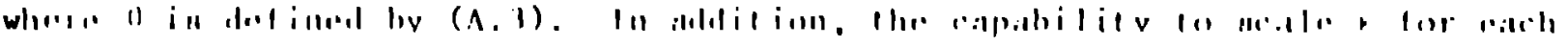

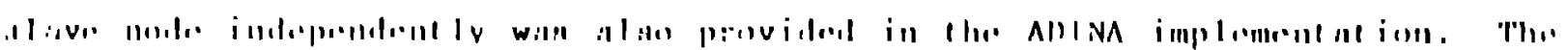

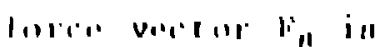




$$
\underline{F}_{g}=\kappa \delta\left[\begin{array}{c}
-g \\
c \\
(1-a) s \\
-(1-a) c \\
\text { ag } \\
-n c
\end{array}\right]
$$

wheres $\delta$ monsures the penetration of nodr $k$ through aogment $\ell-1$, $e$ and ia

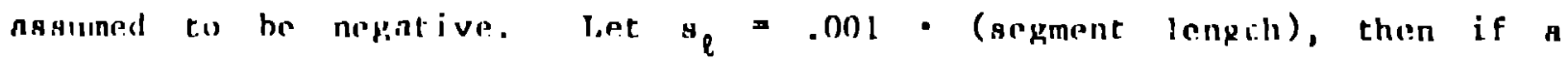
alive node is within $s_{\ell}$ if the mater sagment $\ell-1, \ell$, then $K_{a}$ is

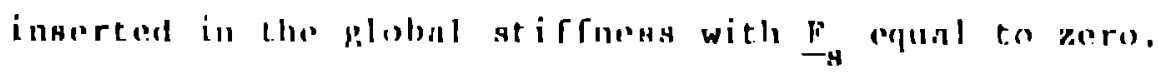

The I ypen of ronetrainte available are: hliding only, tiol, sliding with voids, mal friction sliding with voils. For sliding only, initial gaps in

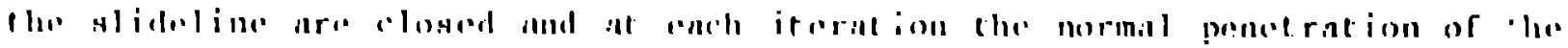

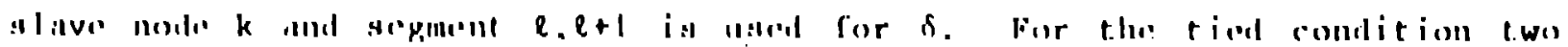

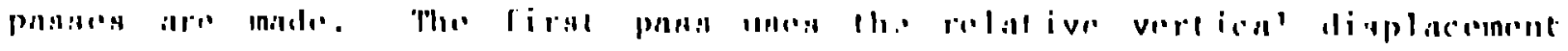

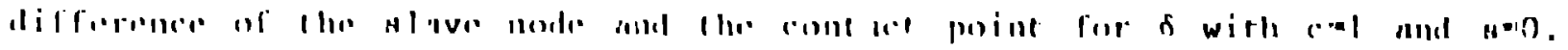

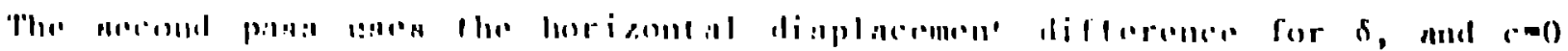

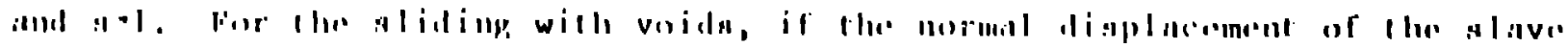

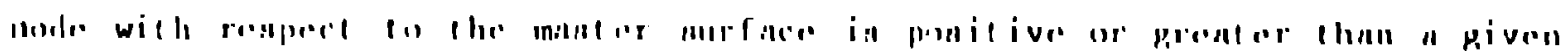

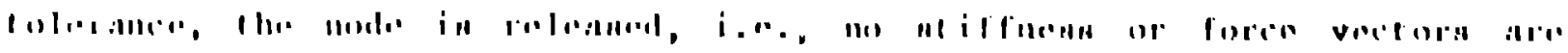

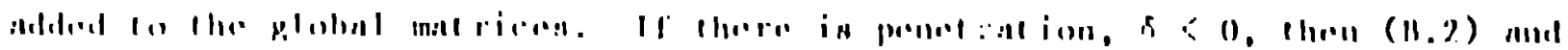

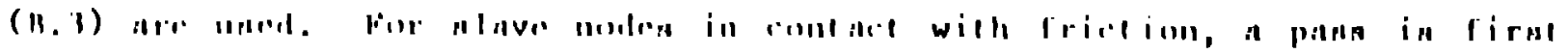

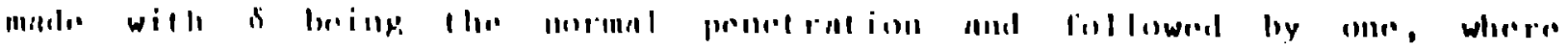

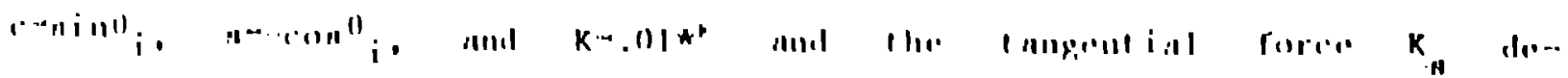

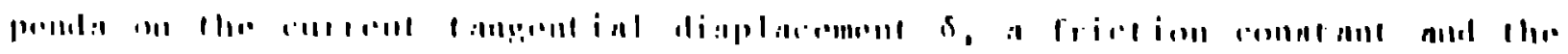


slave node's previous tangential force.

Finally, the convectivity array for each alave node must be updnted at each iteration for both types of slidelines. 


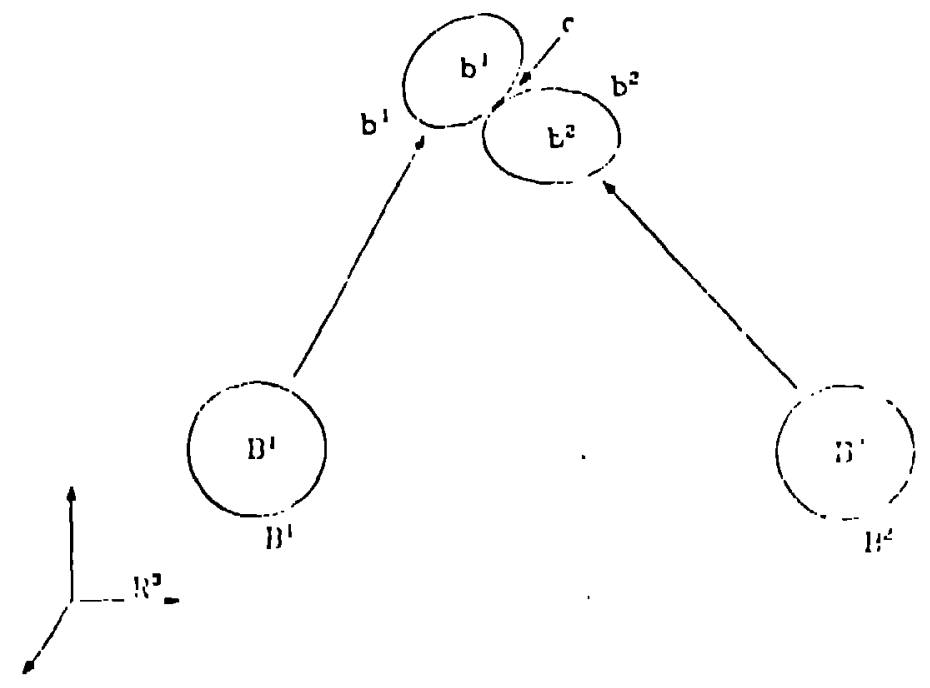

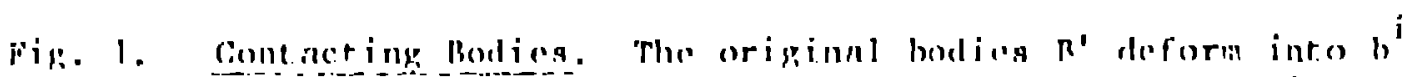

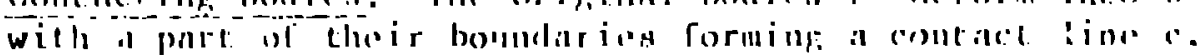

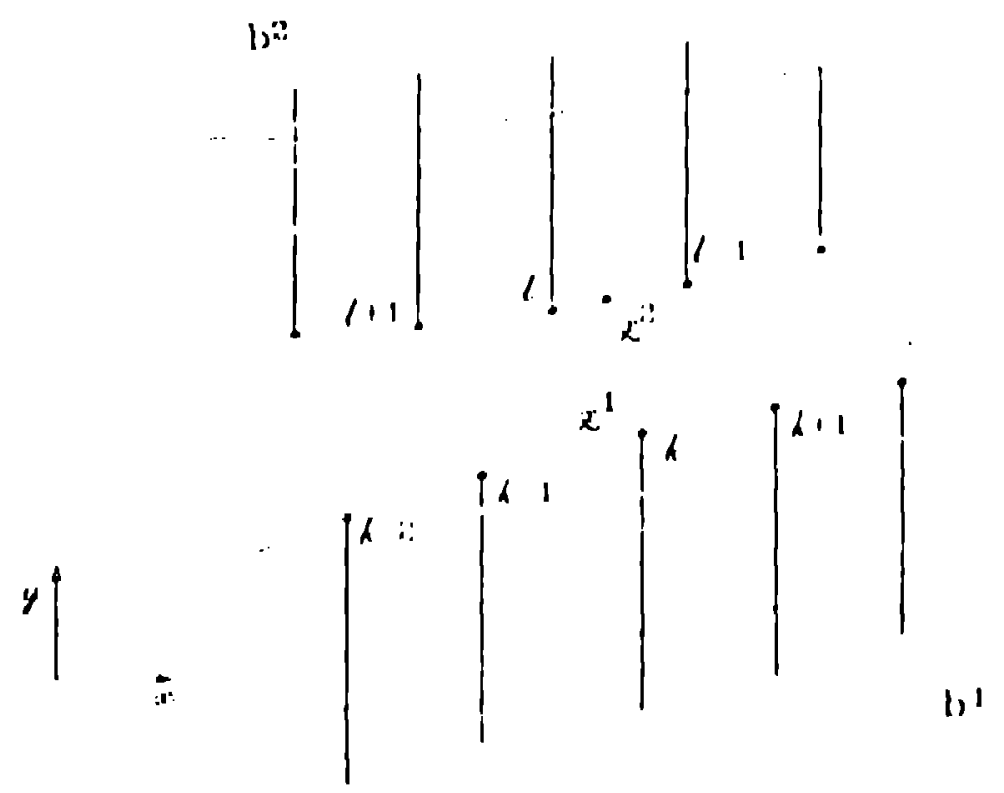

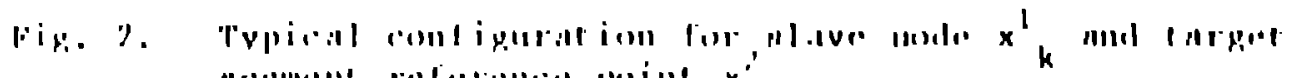

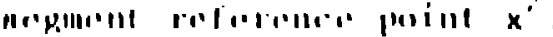




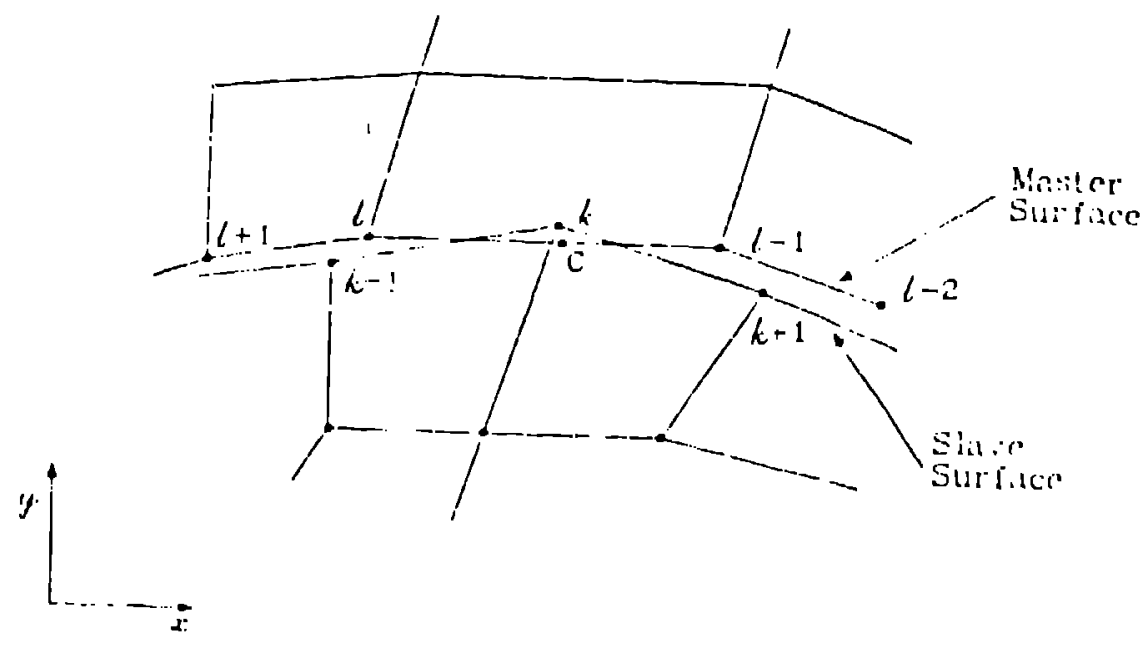

Fig. 3. Slave surface penctratinp the master surfiete at point $c$.

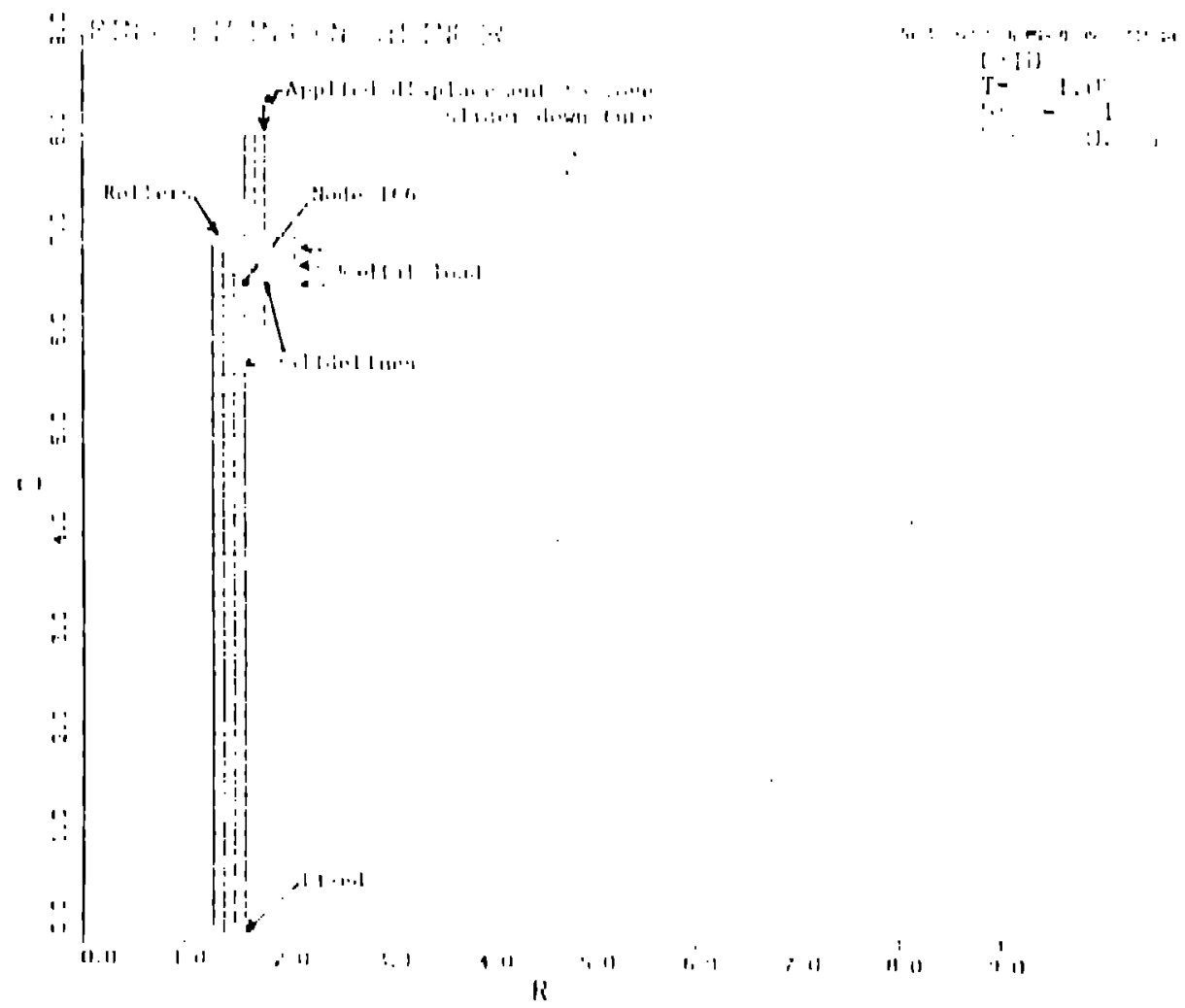

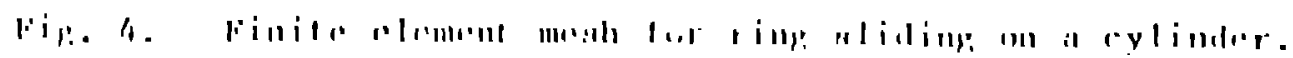



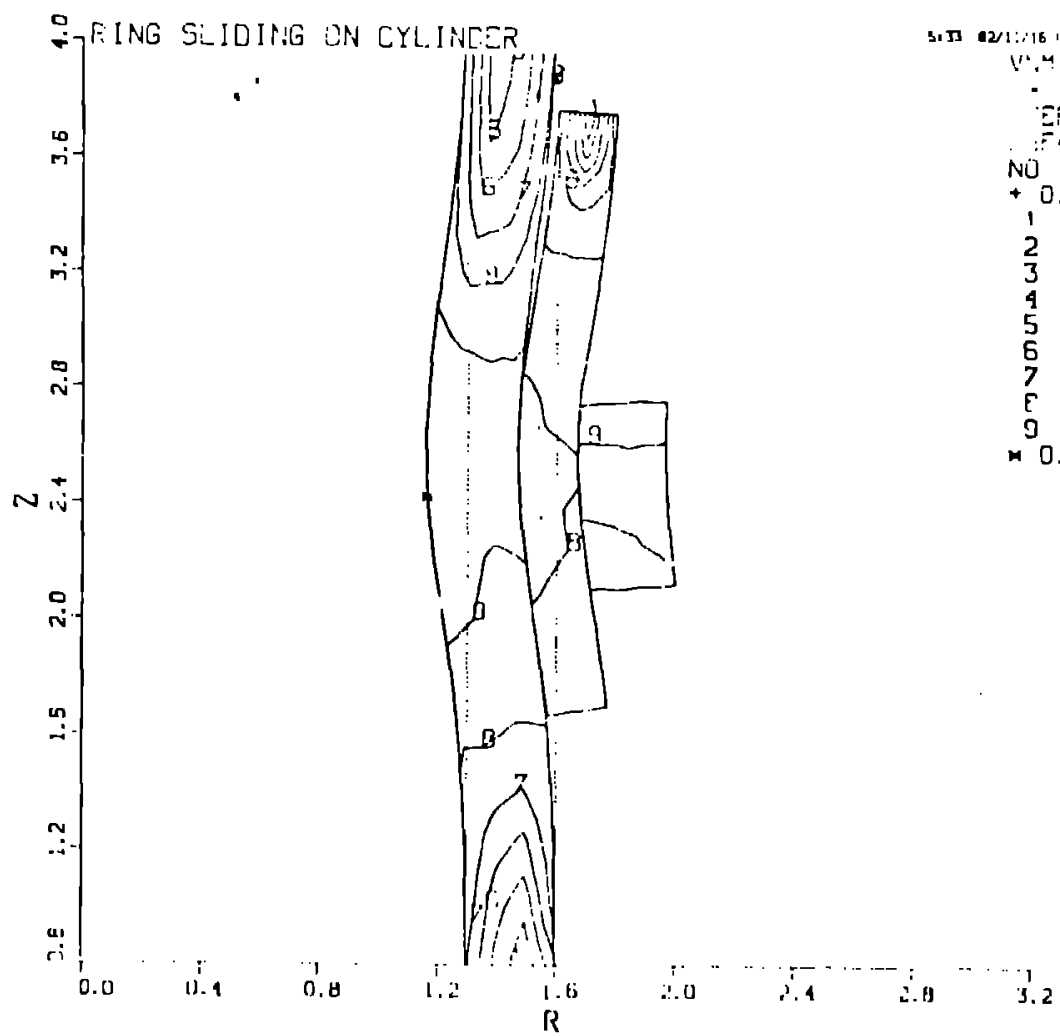

(a) Lagrange Multiplier slideline

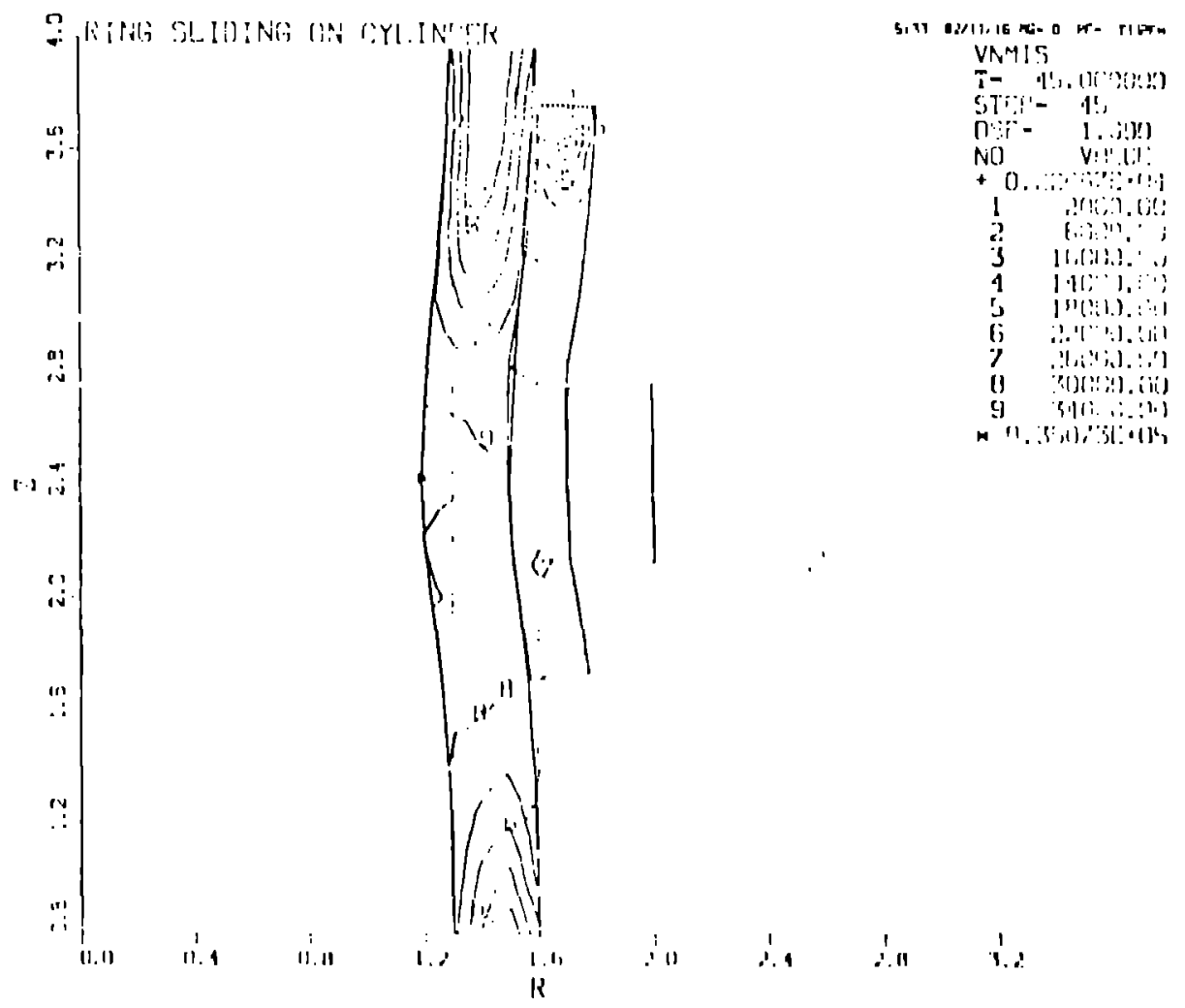

(b) Pantlly Funclion slidaline

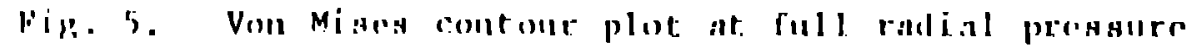




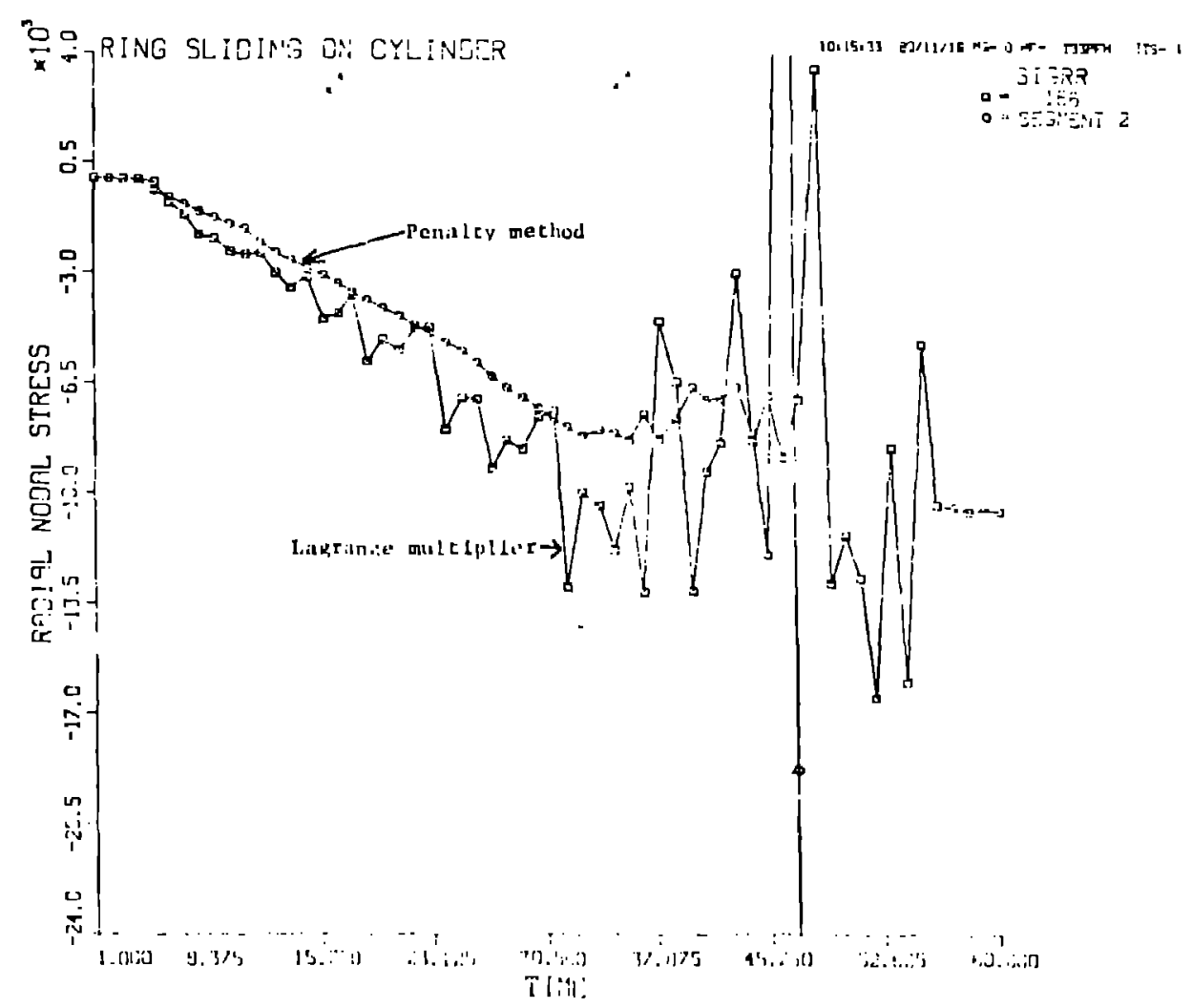

Fig. 6. Comparison of radial stresg at nodis 166 for penalty functi.nil and tagrange multiplier formulation shows smonther behivio: of the penalty method.

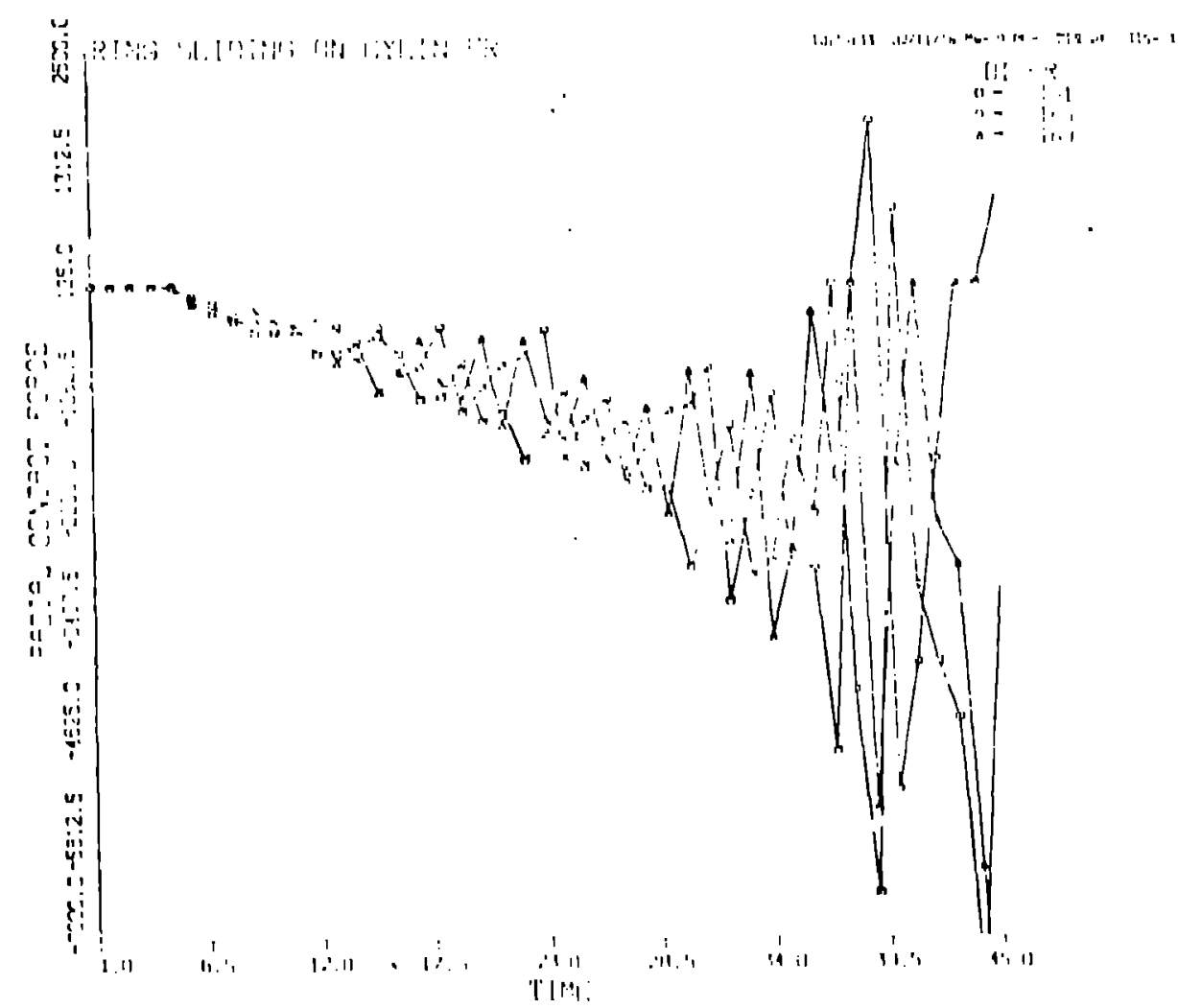

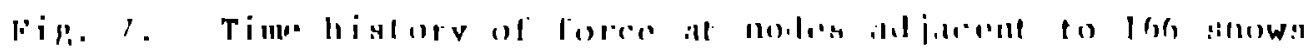

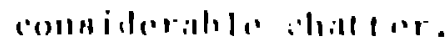




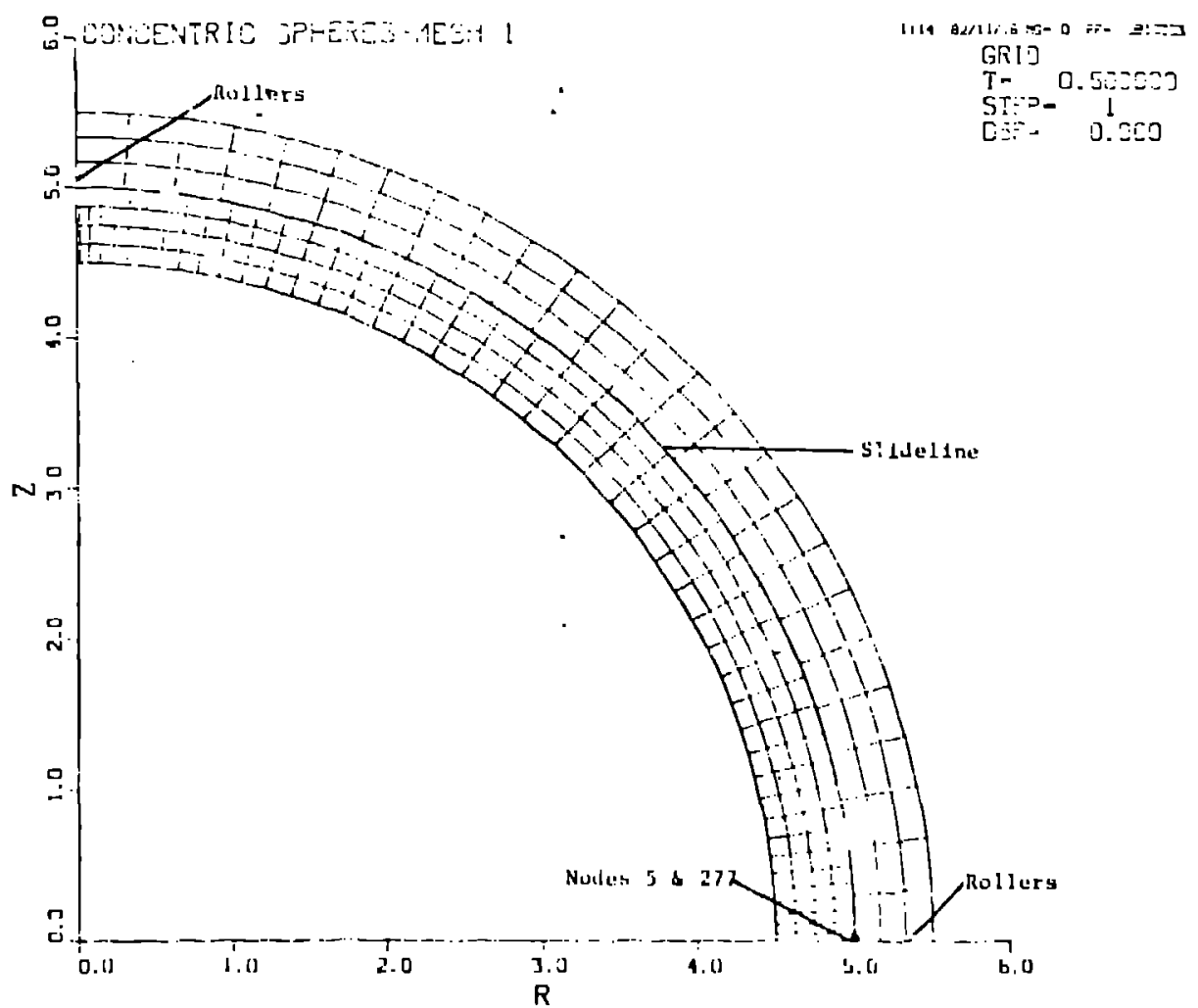

(a) Mesh a

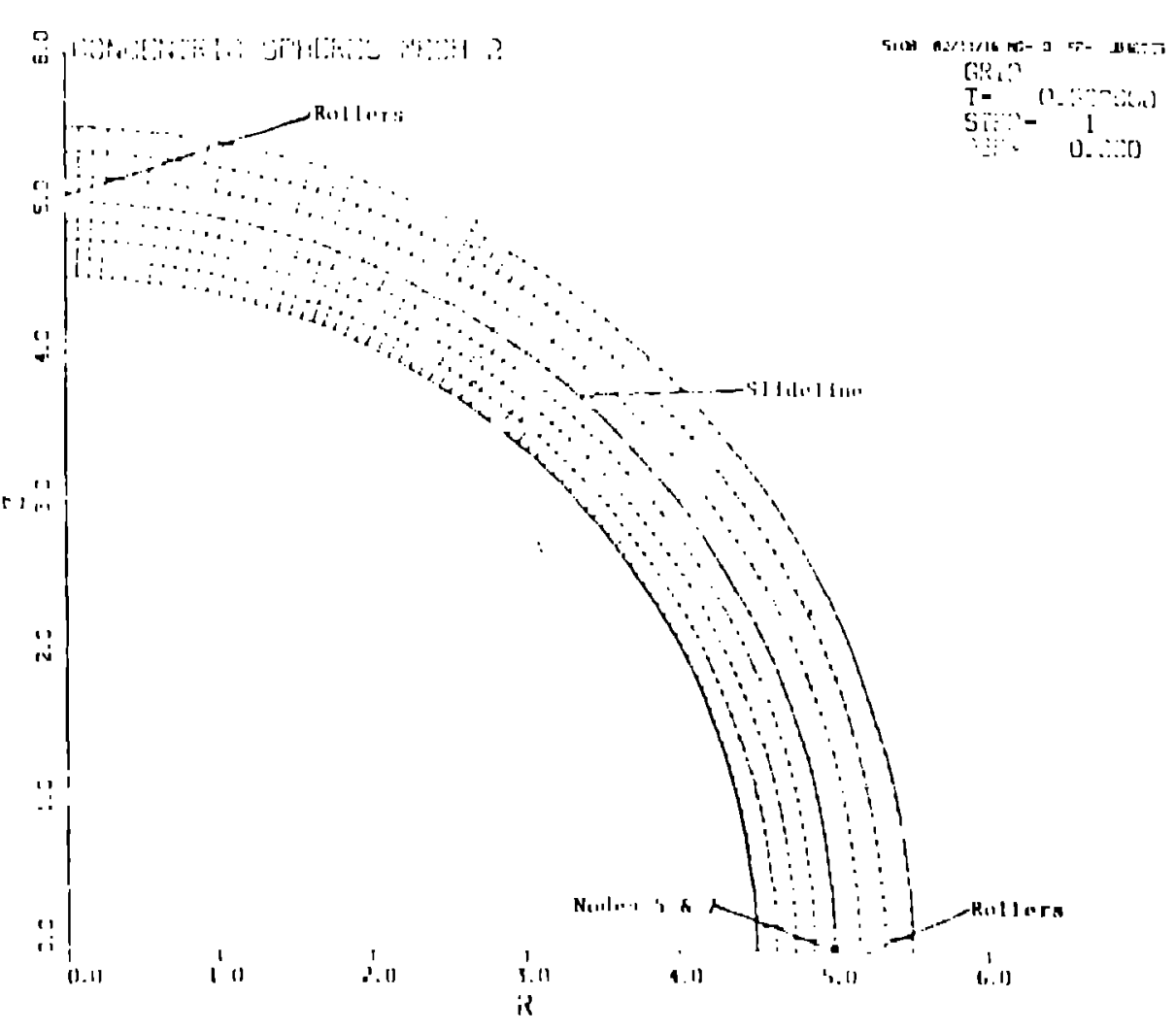

(b) Masih b

fir. R. Two concenteris aphereas acparilted by a small pap 


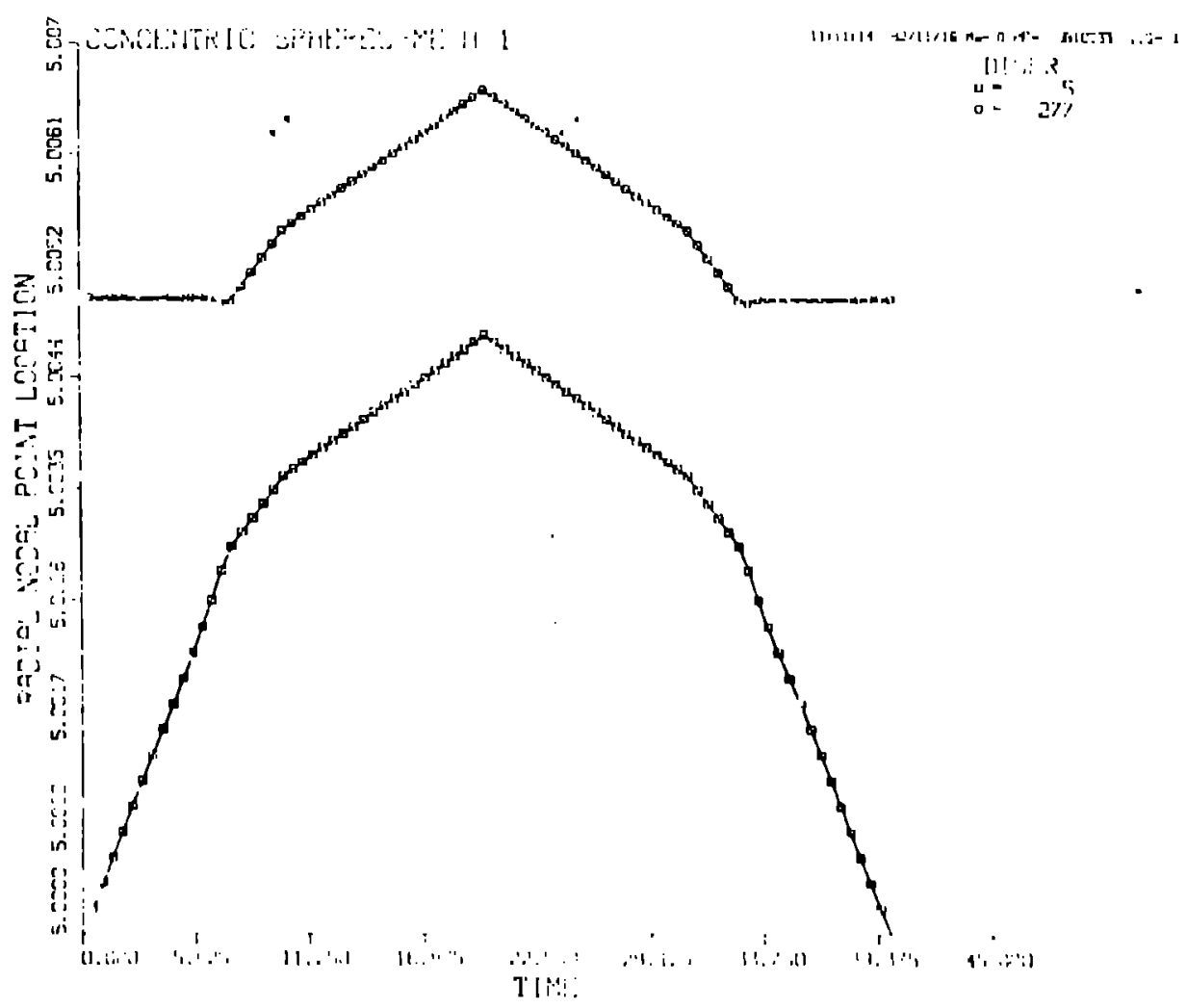

(il) Laprange Multiplier slidinline

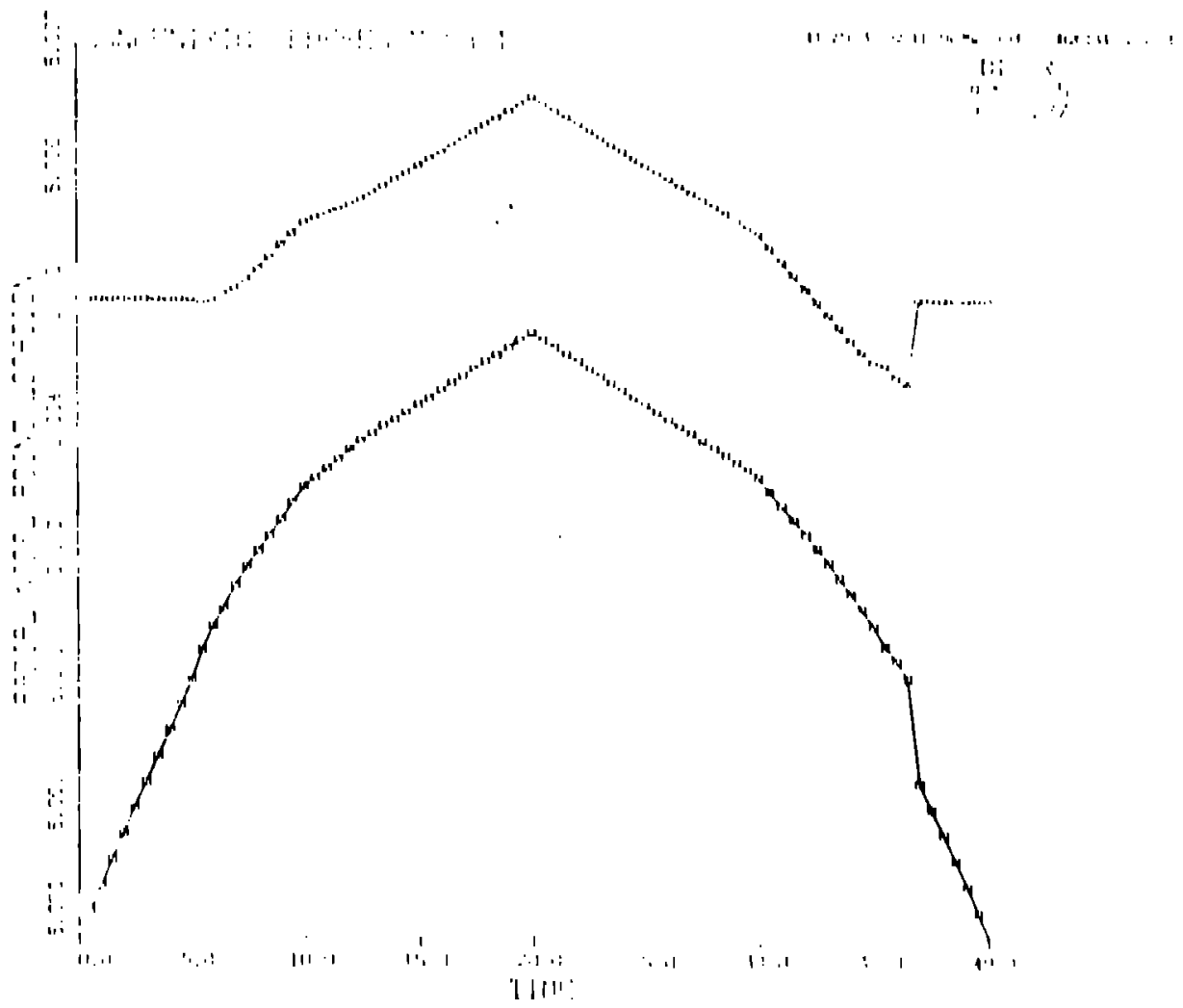

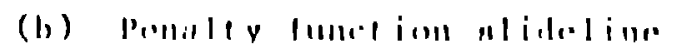

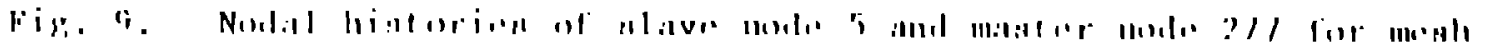

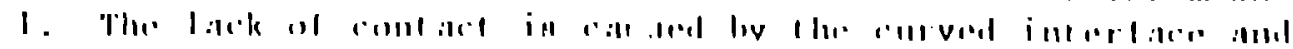

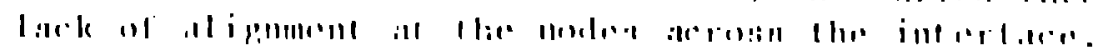




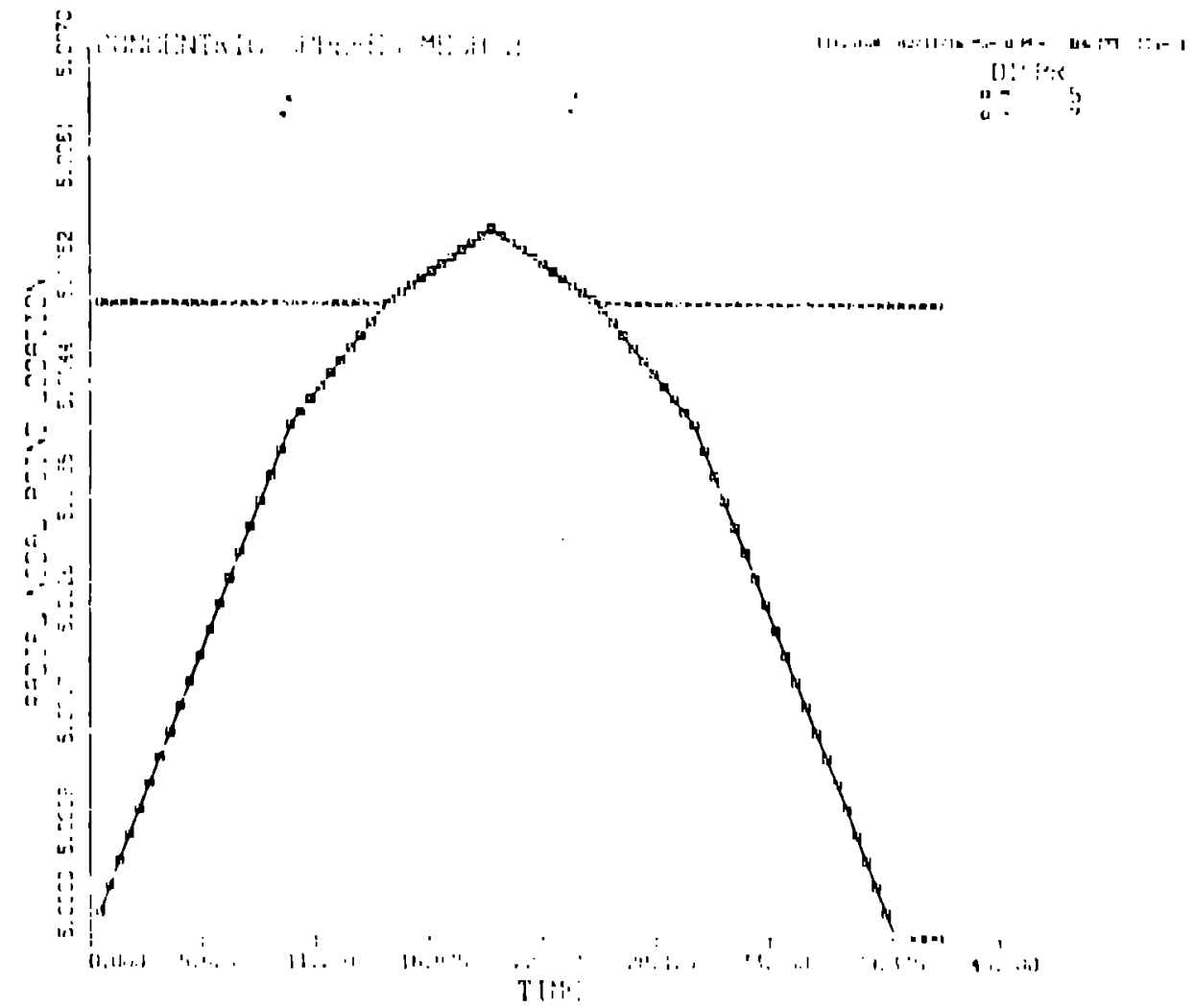

(il) Inyringe Multiplior stideline

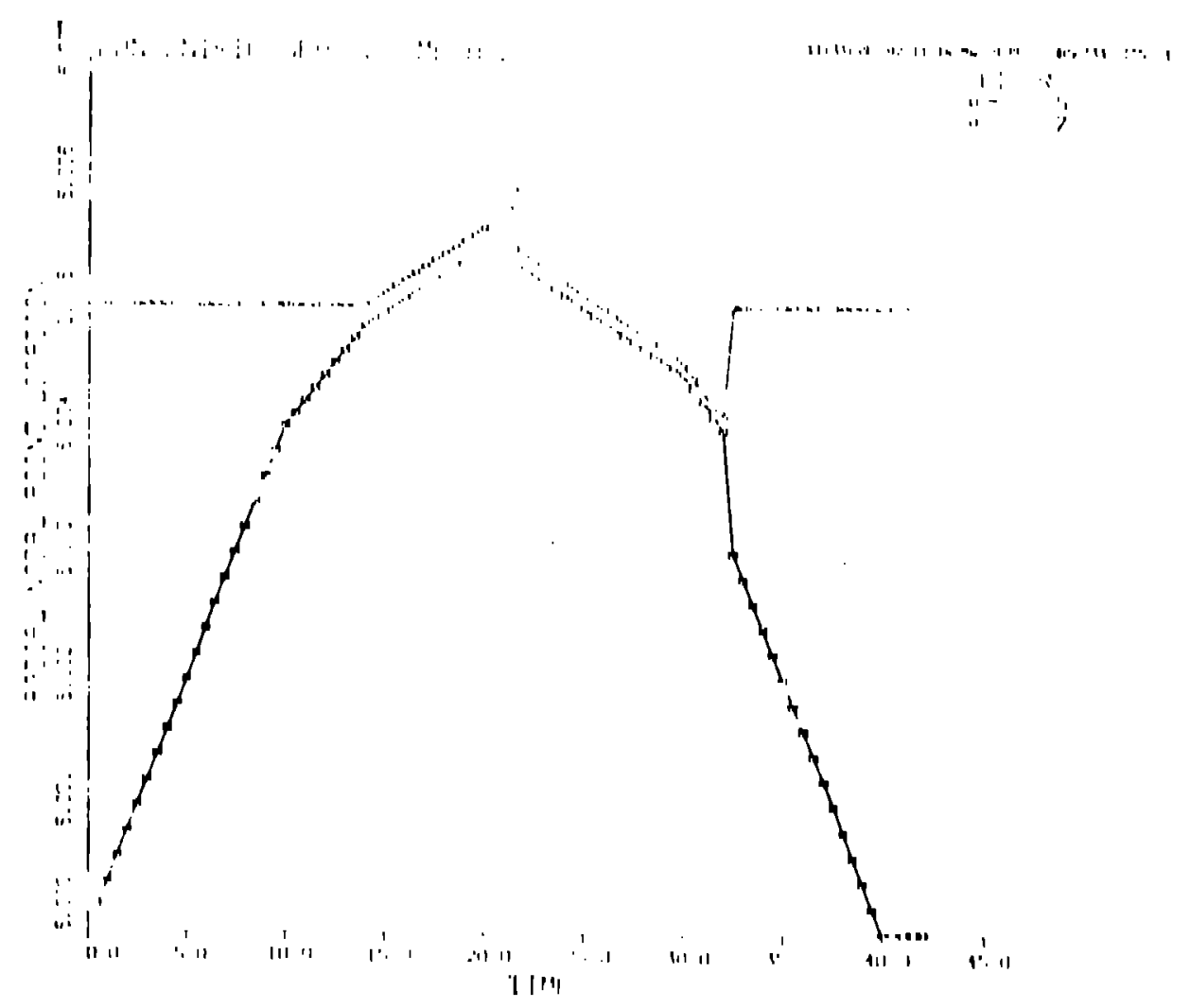

(b) Pronle lunetion nli,leline

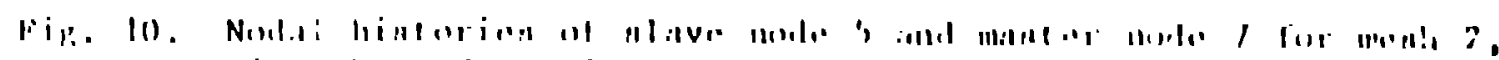

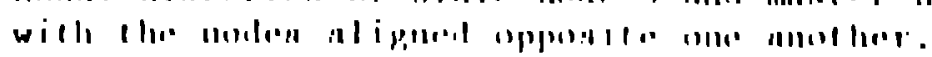




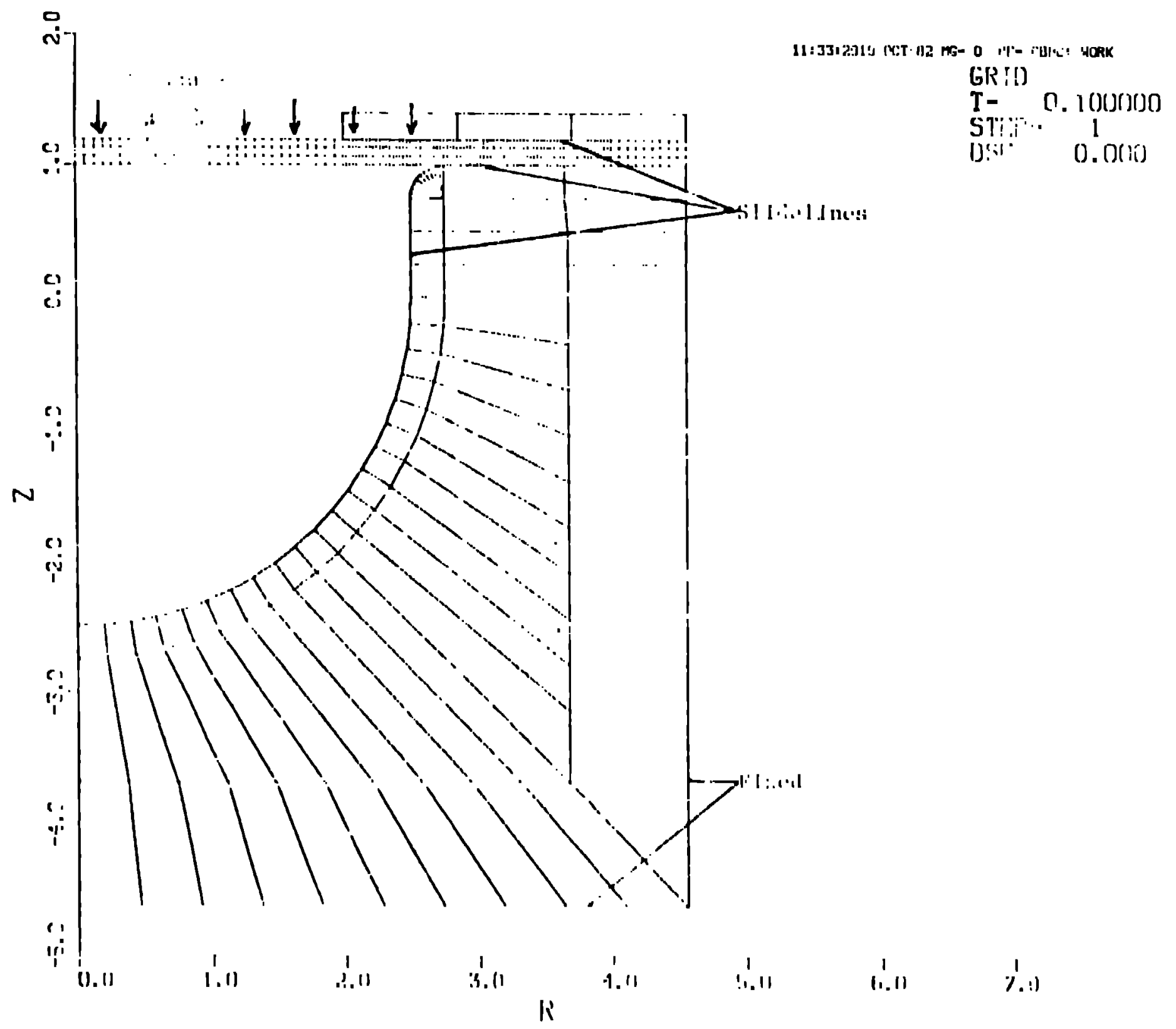

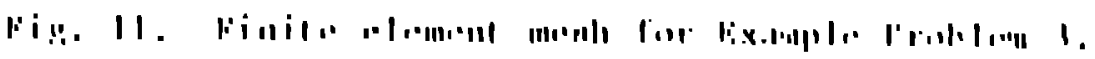




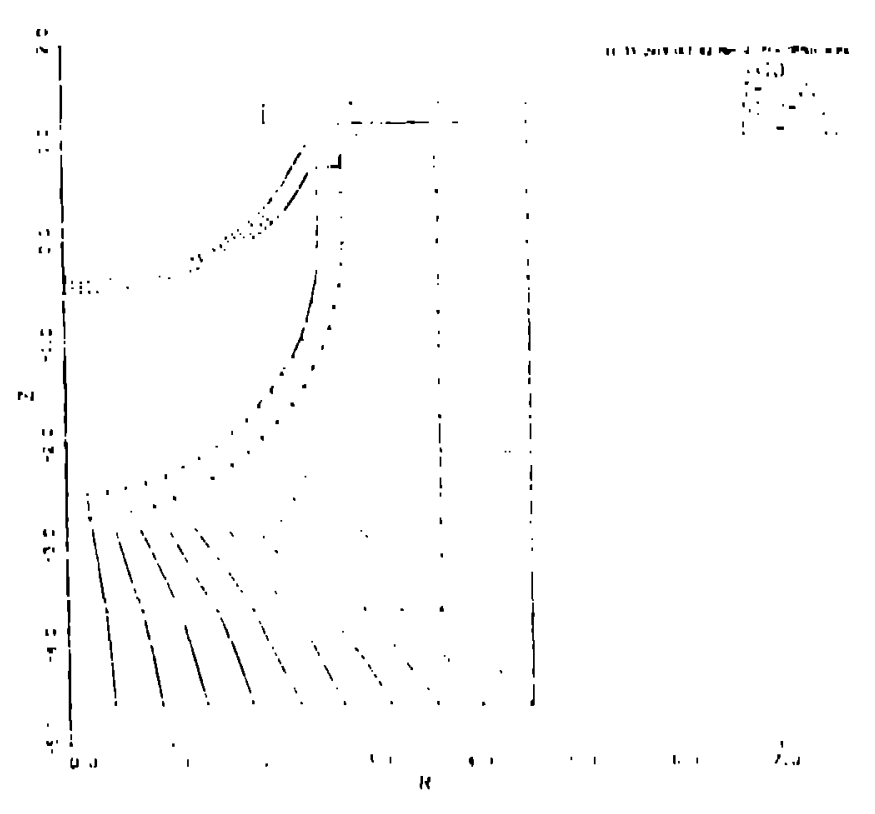

(i)

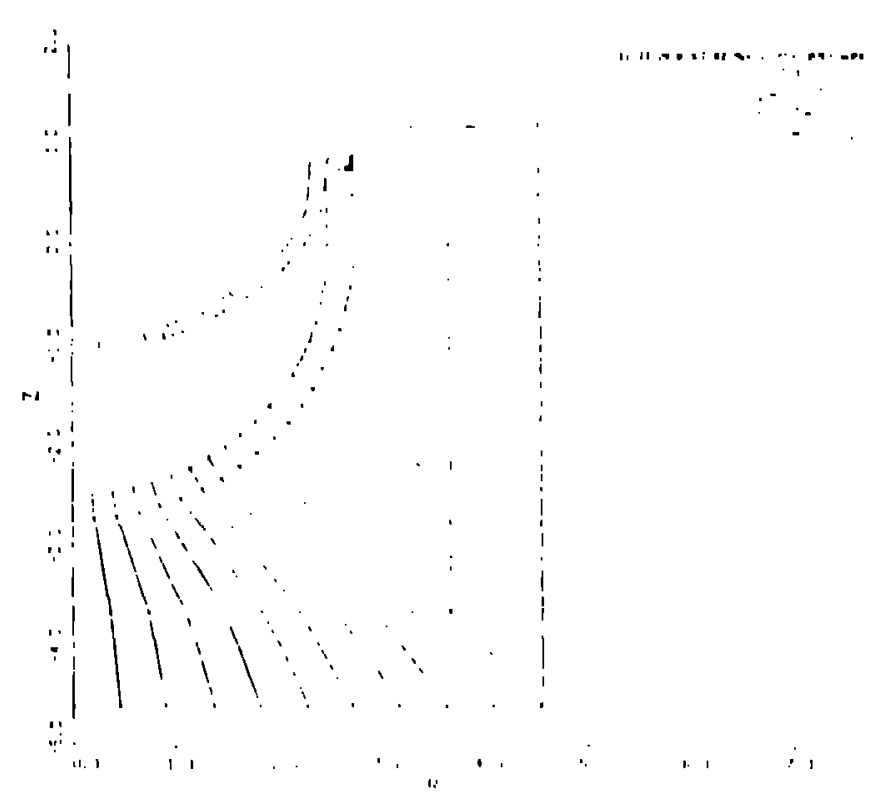

(b)

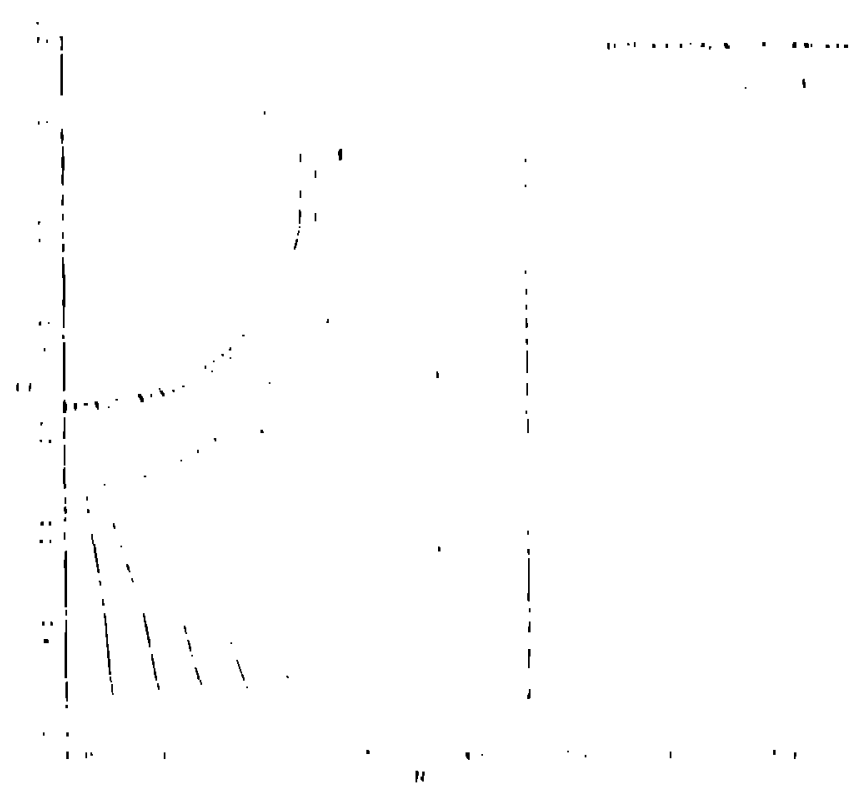

(..)

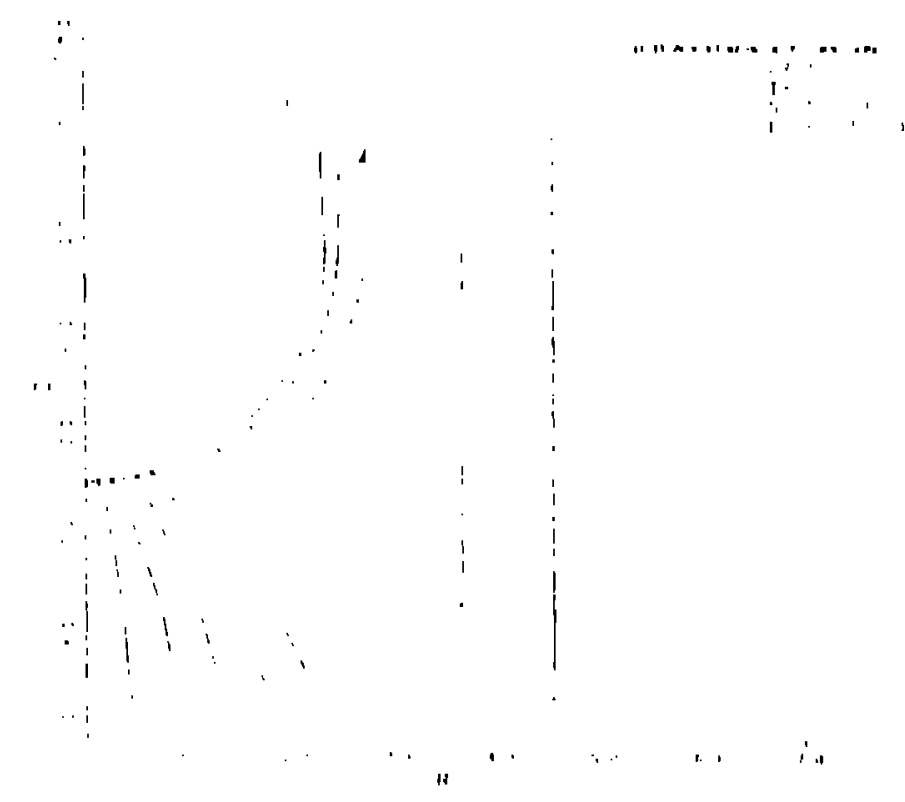

(1) 


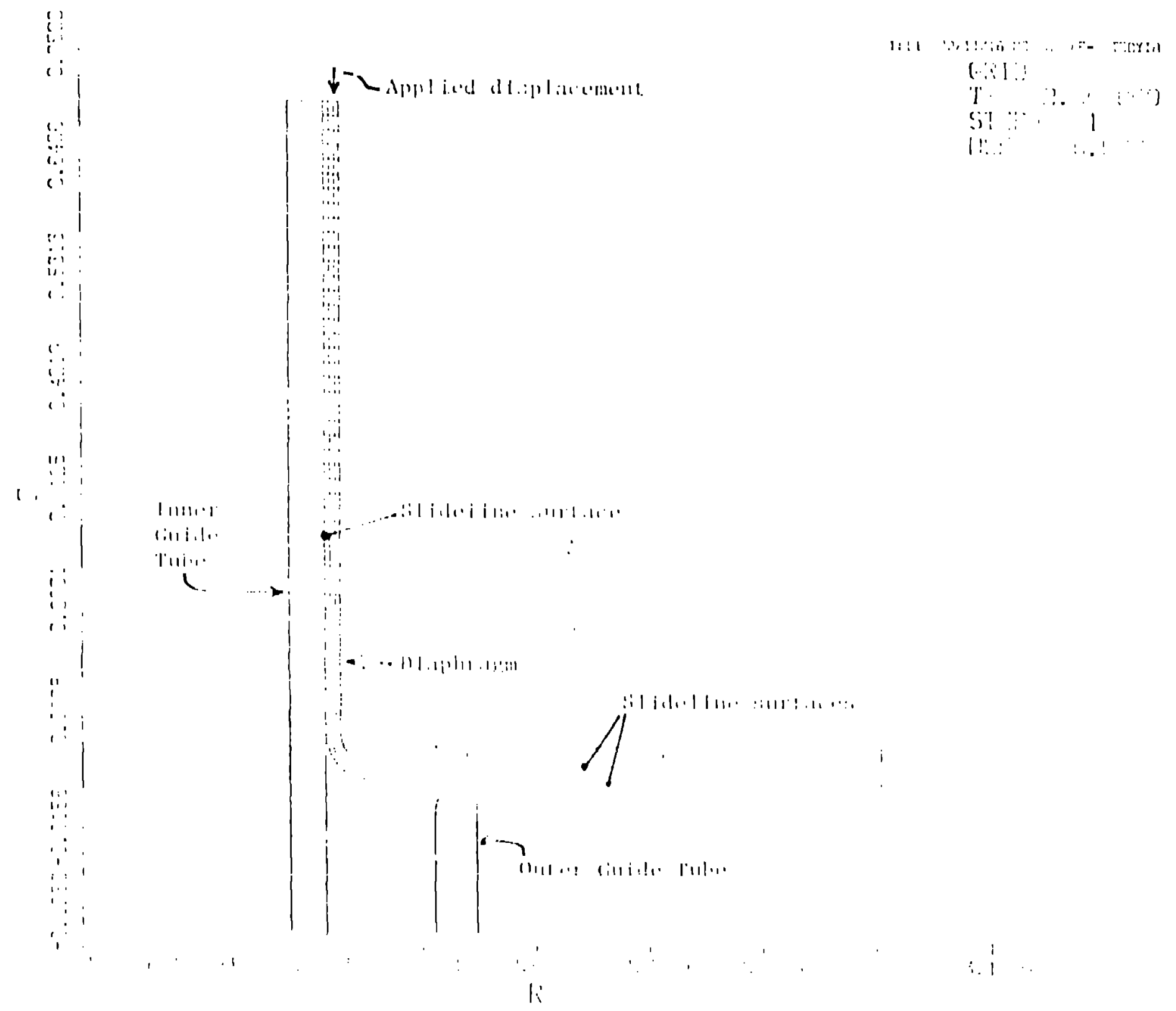

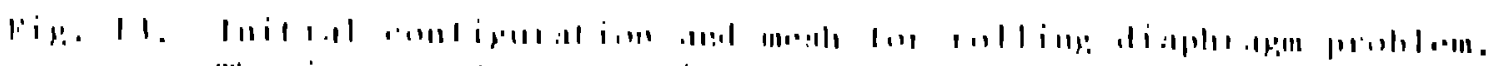

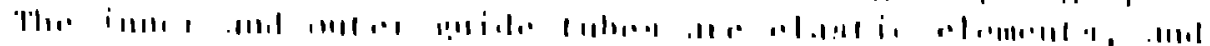
A1. V., 


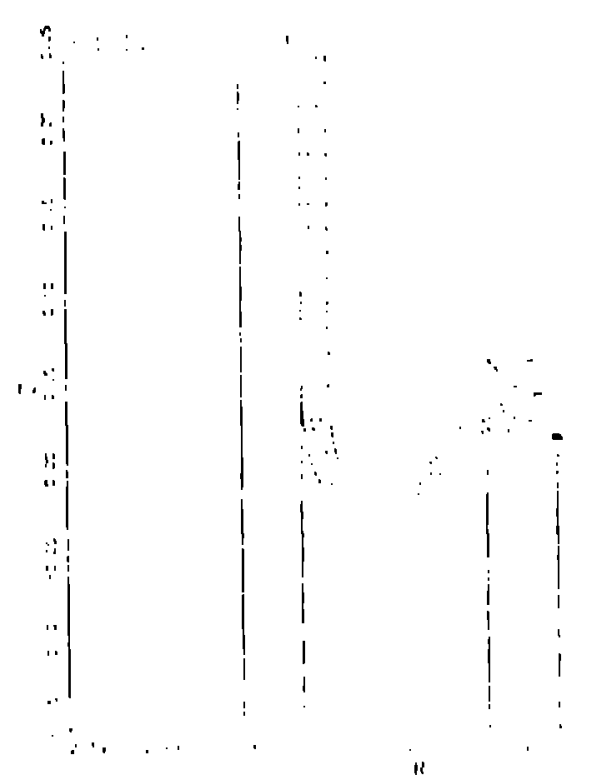

(n)

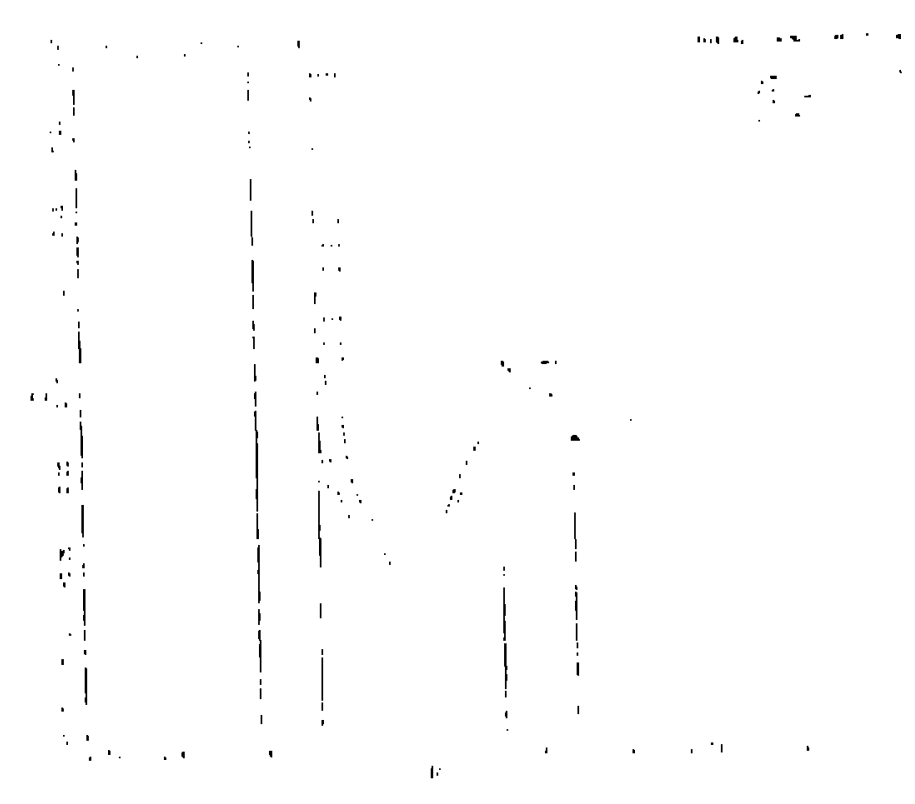

(b)

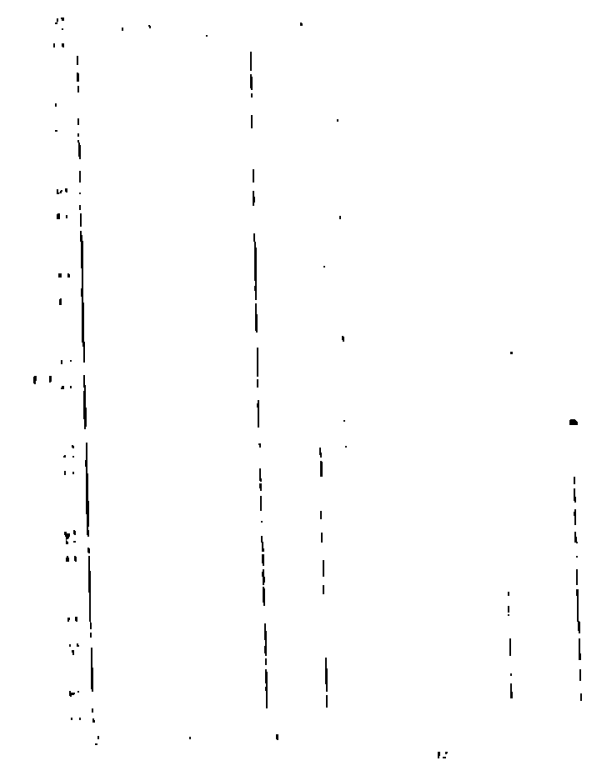

(i)

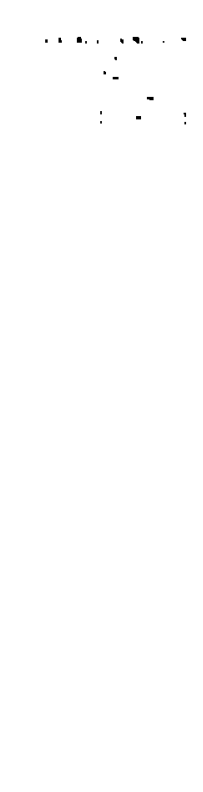

. 